\title{
Manganese in Plants: From Acquisition to Subcellular Allocation
}

\author{
Santiago Alejandro*, Stefanie Höller, Bastian Meier and Edgar Peiter* \\ Plant Nutrition Laboratory, Institute of Agricultural and Nutritional Sciences, Martin Luther University Halle-Wittenberg, Halle \\ (Salle), Germany
}

Manganese $(\mathrm{Mn})$ is an important micronutrient for plant growth and development and sustains metabolic roles within different plant cell compartments. The metal is an essential cofactor for the oxygen-evolving complex (OEC) of the photosynthetic machinery, catalyzing the water-splitting reaction in photosystem II (PSII). Despite the importance of $\mathrm{Mn}$ for photosynthesis and other processes, the physiological relevance of $\mathrm{Mn}$ uptake and compartmentation in plants has been underrated. The subcellular Mn homeostasis to maintain compartmented Mn-dependent metabolic processes like

OPEN ACCESS

Edited by:

Manuel Nieves-Cordones, Center for Edaphology and Applied Biology of Segura, Spanish National

Research Council, Spain

Reviewed by:

Sebastien Thomine,

UMR 9198 Institut de Biologie Intégrative de la Cellule (I2BC), France

Mathieu Pottier,

University of Liège, Belgium

*Correspondence:

Santiago Alejandro

santiago.alejandro-

martinez@landw.uni-halle.de

Edgar Peiter

edgar.peiter@landw.uni-halle.de

Specialty section:

This article was submitted to

Plant Nutrition,

a section of the journal

Frontiers in Plant Science

Received: 05 December 2019

Accepted: 02 March 2020

Published: 26 March 2020

Citation:

Alejandro S, Höller S, Meier B and Peiter E (2020) Manganese in Plants:

From Acquisition to Subcellular

Allocation. Front. Plant Sci. 11:300

doi: 10.3389/fpls.2020.00300 glycosylation, ROS scavenging, and photosynthesis is mediated by a multitude of transport proteins from diverse gene families. However, Mn homeostasis may be disturbed under suboptimal or excessive Mn availability. Mn deficiency is a serious, widespread plant nutritional disorder in dry, well-aerated and calcareous soils, as well as in soils containing high amounts of organic matter, where bio-availability of Mn can decrease far below the level that is required for normal plant growth. By contrast, Mn toxicity occurs on poorly drained and acidic soils in which high amounts of Mn are rendered available. Consequently, plants have evolved mechanisms to tightly regulate Mn uptake, trafficking, and storage. This review provides a comprehensive overview, with a focus on recent advances, on the multiple functions of transporters involved in Mn homeostasis, as well as their regulatory mechanisms in the plant's response to different conditions of $\mathrm{Mn}$ availability.

\footnotetext{
Keywords: manganese transport, manganese uptake, manganese deficiency, manganese toxicity, intracellular distribution, Arabidopsis, rice, barley
}

\section{INTRODUCTION}

Manganese (Mn) is an essential element in virtually all living organisms where it can fulfill two different functions: acting as an enzyme cofactor or as a metal with catalytic activity in biological clusters (Andresen et al., 2018). In humans, Mn functions as a cofactor for a variety of enzymes, including arginase, glutamine synthetase, pyruvate carboxylase, and $\mathrm{Mn}$ superoxide dismutase (MnSOD). But in comparison to other essential micronutrients, such as iron $(\mathrm{Fe})$ and zinc $(\mathrm{Zn})$, whose deficiencies in humans are responsible for major health problems, Mn deficiency in humans is rare. However, Mn poisoning may be encountered more frequently upon overexposure to this metal causing hepatic cirrhosis, polycythemia, dystonia, and Parkinson-like symptoms (Li and Yang, 2018). In plants, $\mathrm{Mn}$ is one of the 17 essential elements for growth and reproduction. It is needed in only small quantities by plants, but is ultimately as critical to growth as are the other nutrients. In photosynthetic organisms, $\mathrm{Mn}$ is an essential element of the metalloenzyme cluster 
of the oxygen-evolving complex (OEC) in photosystem II (PSII). In spite of its importance for photosynthetic activity, Mn homeostasis in plants has been poorly investigated. Nevertheless, Mn deficiency can be a serious plant nutritional disorder in soils with high $\mathrm{pH}$ and high partial pressure of $\mathrm{O}_{2}\left(\mathrm{pO}_{2}\right)$, where the bio-availability of $\mathrm{Mn}$ can decrease far below the level that is required for normal plant growth (Broadley et al., 2012). Fertilization with Mn salts at soil level is often not effective, since soluble $\mathrm{Mn}\left(\mathrm{Mn}^{2+}\right)$ is rapidly converted to plantunavailable Mn oxides, particularly in sandy alkaline soils. (In this review, we use the general term "Mn," unless we refer to a specific oxidation state). However, it has been argued that the application of $\mathrm{Mn}$ fertilizers to the soil can be an effective way to alleviate $\mathrm{Mn}$ deficiencies, but only if soil $\mathrm{pH}$ is also corrected (White and Greenwood, 2013). Foliar Mn application can supply sufficient Mn to overcome Mn deficiency, but this strategy is expensive and often impractical for farmers on marginal lands. Moreover, foliar Mn sprays are only effective for a limited time period since $\mathrm{Mn}$ is very little mobile in the plant and does not remobilize from older leaves to $\mathrm{Mn}$ deficient young leaves ( $\mathrm{Li}$ et al., 2017). On the other extreme, Mn toxicity can occur in poorly drained and in strongly acidic soils, where it is usually associated with other acidity-related soil fertility problems, such as aluminum toxicity and deficiencies of calcium (Ca), magnesium (Mg), and molybdenum (Mo) (Goulding, 2016).

Depending on Mn availability, plants either need to efficiently acquire and utililize Mn under limiting conditions, or to detoxify the metal under superfluous supply. Transport processes are at the core of those adaptations. In the past, $\mathrm{Mn}$ transporters have been identified at the molecular level in many eukaryotic organisms (Pittman, 2005). Furthermore, recent progress in Mn homeostasis has mainly focused on Arabidopsis and rice, which represent dicot and graminaceous monocot plants, respectively (Socha and Guerinot, 2014; Shao et al., 2017). Only recently, transporters involved in uptake and subcellular distribution of Mn have been characterized in a wider range of plant species. This article reviews the current knowledge of Mn uptake, translocation and subcellular distribution, as well as the functions of $\mathrm{Mn}$ in different plant species. Table 1 lists the Mn transporters discussed in the text.

\section{FUNCTIONS OF MANGANESE IN PLANTS}

Mn plays a role in diverse processes of a plant's life cycle such as photosynthesis, respiration, scavenging of reactive oxygen species (ROS), pathogen defense, and hormone signaling. In Arabidopsis, 398 enzymes are predicted to contain $\mathrm{Mn}$ in the metal-binding site (The UniProt Knowledgebase ${ }^{1}$ ). Among them, $20 \%$ showed an experimental evidence to require $\mathrm{Mn}$ as a cofactor. In many enzymes, $\mathrm{Mn}$ is interchangeable with other divalent cations such as $\mathrm{Ca}$, cobalt $(\mathrm{Co})$, copper $(\mathrm{Cu}), \mathrm{Mg}$, or $\mathrm{Zn}$.

\footnotetext{
${ }^{1}$ http://www.uniprot.org, accessed 20 October 2019
}

In plants, only the OEC in PSII, MnSOD, and oxalate oxidase have been shown to require exclusively $\mathrm{Mn}$.

The most-well-studied function in plant metabolism that depends on $\mathrm{Mn}$ is the water-splitting reaction in PSII, which is the first step of photosynthesis. This process requires the tetra-Mn cluster $\mathrm{Mn}_{4} \mathrm{O}_{5} \mathrm{Ca}$ to split two water molecules into four electrons, four protons, and molecular $\mathrm{O}_{2}$ (Bricker et al., 2012). However, the delivery of $\mathrm{Mn}^{2+}$ and $\mathrm{Ca}^{2+}$ to the OEC reaction center in land plants is still under investigation. In the unicellular photosynthetic organism Synechocystis, PratA functions as an assembly factor and chaperone protein for efficient delivery of $\mathrm{Mn}$ to the PSII reaction core (Stengel et al., 2012). In green plants, it is speculated that the extrinsic protein PsbP, the closest homolog to PratA, acts as a Mn carrier protein to introduce $\mathrm{Mn}$ into the OEC reaction center, where it subsequently stabilizes the Mn cluster in association with PsbO and PsbQ (Bondarava et al., 2007).

Another process in plants dependent on $\mathrm{Mn}$ is the detoxification of ROS. In plant cells, ROS are formed mainly in chloroplasts, mitochondria, peroxisomes, and in the cytosol. $\mathrm{Mn}$ is a cofactor of MnSODs located in mitochondria as also in peroxisomes (Bowler et al., 1994; Corpas et al., 2017). In addition, oxalate oxidase is a Mn-dependent enzyme which catalyzes the oxidation of oxalate to $\mathrm{CO}_{2}$ coupled with a reduction of $\mathrm{O}_{2}$ to $\mathrm{H}_{2} \mathrm{O}_{2}$ (Requena and Bornemann, 1999). Oxalate oxidase is located in the apoplast, where it is involved in pathogen defense likely by the generation of microcidal concentrations of $\mathrm{H}_{2} \mathrm{O}_{2}$ and by the formation of effective barriers against pathogen penetration by $\mathrm{H}_{2} \mathrm{O}_{2}$-mediated lignification (Lane, 2002). Oxalate oxidase activity has been identified mainly in monocot plant species including wheat, barley, and rice (Svedruzic et al., 2005). Interestingly, germin-like proteins (GLPs) in Arabidopsis, which are homologous to oxalate oxidase, showed neither oxalate oxidase activity nor a Mndependent activation (Membré et al., 2000; Li et al., 2016). Intriguingly, the $\mathrm{Mn}^{2+}$ cation itself may act as an antioxidant molecule. In fact, it has been shown in yeast that elevated intracellular $\mathrm{Mn}$ was associated with a reduction of oxidative damage in yeast cells (Reddi et al., 2009). It is likely that Mnphosphate (Mn-P) complexes act as antioxidants whereby the Mn speciation is altered by changes in phosphate concentrations (McNaughton et al., 2010).

Furthermore, $\mathrm{Mn}$ is an important cofactor of enzymes involved in isoprenoid biosynthesis (Wilkinson and Ohki, 1988; Köllner et al., 2008). Mn and Mg are two major cofactors of terpene synthases (Rohdich et al., 2006; Köllner et al., 2008). Therefore, it has been proposed that different patterns of plant terpene profiles are often closely correlated with $\mathrm{Mg} / \mathrm{Mn}$ ratios rather than with concentrations of each cofactor element alone in the growth media (Farzadfar et al., 2017). Beside this, Mn is involved in lignin biosynthesis at two different levels: (i) $\mathrm{Mn}$, besides $\mathrm{Mg}$, can serve as cofactor of the phenylalanine ammonia-lyase (PAL) (Engelsma, 1972), a key enzyme in the phenylpropanoid pathway to produce monolignols; (ii) Lignin can be synthesized from monolignols that are oxidized by $\mathrm{Mn}^{3+}$ into monolignol radicals, which can then be added to existing phenolic groups to form lignin polymers (Önnerud et al., 2002). 
Intriguingly, it has been shown that $\mathrm{Mn}$ can replace $\mathrm{Mg}$ in the active site of some enzymes of the photosynthetic pathway, including Ribulose-1,5-bisphosphate carboxylase/oxygenase (Rubisco), changing the functional role of these enzymes (Bloom and Lancaster, 2018; Bloom, 2019). Furthermore, in vitro experiments demonstrated that $\mathrm{Mn}$ is an important cofactor in abscisic acid (ABA) and auxin signaling by activating PP2C phosphatases and IAA-amino acid conjugate hydrolases, respectively (LeClere et al., 2002; Meinhard et al., 2002; Schweighofer et al., 2004). Since diverse Golgi-localized glycosyl transferases require $\mathrm{Mn}$ for their activity, $\mathrm{Mn}$ is also essential for protein glycosylation and the biosynthesis of pectin and hemicellulose polymers (Egelund et al., 2006; Strasser et al., 2007; Basu et al., 2015). Other enzymes that require $\mathrm{Mn}$ as a cofactor are purple acid phosphatases (PAPs) (Schenk et al., 1999; Venkidasamy et al., 2019). Also, different decarboxylases (e.g., NAD malic enzyme) and dehydrogenases (e.g., phosphoenolpyruvate carboxylase) of the tricarboxylic acid cycle can be activated by Mn, but in many cases Mn can be replaced by Mg (Burnell, 1988; Gregory et al., 2009).

Another Mn-dependent process lies in the deposition of cuticular waxes in leaves. In barley, it has been demonstrated that Mn deficiency may decrease the cuticular wax layer, which leads to a higher transpiration rate (Hebbern et al., 2009).
Moreover, Mn deficiency caused a decrease of cuticular waxes in Arabidopsis leaves (Alejandro et al., 2017).

In addition, $\mathrm{Mn}$ plays a role in such diverse processes as chloroplast development (Rohdich et al., 2000; Hsieh et al., 2008), purine and urea catabolism (Werner et al., 2008; Cao et al., 2010), phospholipid biosynthesis (Collin et al., 1999; Nowicki et al., 2005), $\mathrm{Ca}^{2+}$ signaling (Kim et al., 2003; Hashimoto et al., 2012), DNA repair (Takahashi et al., 2007; Szurmak et al., 2008), or histidine biosynthesis (Glynn et al., 2005).

\section{MANGANESE DEFICIENCY AND TOXICITY}

In plants, Mn deficiency often occurs as a latent disorder, without clear visual symptoms. Thus, the magnitude to which Mn deficiency affects crop yield is difficult to quantify. The critical concentration for $\mathrm{Mn}$ deficiency is generally below 10-20 mg. $\mathrm{kg}^{-1}$ dry weight (Broadley et al., 2012). One of the consequences of $\mathrm{Mn}$ deficiency in plants is an impaired growth, leading to a decrease in biomass (Longnecker et al., 1991; Hebbern et al., 2005; Pedas et al., 2005). This can be caused by lower numbers of chloroplasts, lower net photosynthetic efficiency, and a decrease in chlorophyll content

TABLE 1 | Manganese transport proteins reviewed in this article.

\begin{tabular}{|c|c|c|c|c|c|}
\hline Family/name & $\begin{array}{l}\text { Organ(s)/tissue(s) } \\
\text { expression }\end{array}$ & $\begin{array}{l}\text { Subcellular } \\
\text { localization }\end{array}$ & $\begin{array}{l}\text { Gene expression } \\
\text { response }\end{array}$ & Other substrates & References \\
\hline \multicolumn{6}{|l|}{ CaCA } \\
\hline AtCAX2 & $\begin{array}{l}\text { Root (stele and root tip), } \\
\text { stem, leaf, flower, pollen, } \\
\text { fruit }\end{array}$ & Tonoplast & $\begin{array}{l}\text { Unaffected by }+\mathrm{Cu},+\mathrm{Mn} \text {, } \\
+\mathrm{Zn}\end{array}$ & $\mathrm{Ca}, \mathrm{Cd}$ & $\begin{array}{l}\text { Hirschi et al., 2000; } \\
\text { Shigaki et al., 2003; } \\
\text { Pittman et al., 2004; } \\
\text { Edmond et al., } 2009\end{array}$ \\
\hline AtCAX4 & Root, stem, leaf, flower, fruit & Tonoplast & $\begin{array}{l}\text { Up-regulated by }+\mathrm{Mn},+\mathrm{Ni} \text {, } \\
\text {-Ca }\end{array}$ & $\mathrm{Cd}, \mathrm{Ca}, \mathrm{Zn}$ & $\begin{array}{l}\text { Cheng et al., 2002; } \\
\text { Koren'kov et al., 2007; } \\
\text { Mei et al., } 2009\end{array}$ \\
\hline AtCAX5 & Root, stem, leaf, flower, fruit & Tonoplast & $\begin{array}{l}\text { Up-regulated by }+\mathrm{Mn} \\
\text { down-regulated by }+\mathrm{Zn}\end{array}$ & $\mathrm{Ca}$ & Edmond et al., 2009 \\
\hline HvCAX2 & Root, leaf, seed & - & $\begin{array}{l}\text { Up-regulated by }+\mathrm{Ca},+\mathrm{Na} \\
\text { unaffected by }+\mathrm{Mn}\end{array}$ & $\mathrm{Ca}$ & Edmond et al., 2009 \\
\hline LeCAX2 & Root, leaf, fruit & - & - & $\mathrm{Ca}$ & Edmond et al., 2009 \\
\hline OsCAX1a & Root, shoot, flower, seed & Tonoplast & - & $\mathrm{Ca}$ & Kamiya et al., 2005 \\
\hline OsCAX3 & Root, shoot, flower, seed & - & - & $\mathrm{Ca}$ & Kamiya et al., 2005 \\
\hline OsCAX4 & Root & - & Up-regulated by $+\mathrm{Ca}$ & $\mathrm{Ca}, \mathrm{Cu}$ & Yamada et al., 2014 \\
\hline VvCAX3 & Root, stem, leaf, fruit & Tonoplast & $\begin{array}{l}\text { Up-regulated by }+\mathrm{Ca},+\mathrm{Na} \\
\text { unaffected by }+\mathrm{Mn}\end{array}$ & $\mathrm{Ca}, \mathrm{Cu}, \mathrm{Li}, \mathrm{Na}$ & Martins et al., 2017 \\
\hline AtCCX3 & Root, stem, leaf, flower & $\begin{array}{l}\text { Tonoplast, } \\
\text { endomembranes }\end{array}$ & $\begin{array}{l}\text { Up-regulated by }+\mathrm{K},+\mathrm{Na} \\
\text { unaffected by }+\mathrm{Mn}\end{array}$ & $\mathrm{K}, \mathrm{Na}$ & Morris et al., 2008 \\
\hline \multicolumn{6}{|l|}{ BICAT } \\
\hline AtBICAT1/PAM71/CCHA1 & Leaf & $\begin{array}{l}\text { Chloroplast } \\
\text { (thylakoid } \\
\text { membrane) }\end{array}$ & Unaffected by $+\mathrm{Mn}$ & $\mathrm{Ca}$ & $\begin{array}{l}\text { Schneider et al., 2016; } \\
\text { Wang et al., 2016; } \\
\text { Eisenhut et al., 2018; } \\
\text { Frank et al., } 2019\end{array}$ \\
\hline AtBICAT2/CMT1 & Root, stem, leaf, flower, fruit & $\begin{array}{l}\text { Chloroplast (inner } \\
\text { envelope) }\end{array}$ & Down-regulated by $+\mathrm{Mn}$ & $\mathrm{Ca}, \mathrm{Mg}$ & $\begin{array}{l}\text { Eisenhut et al., 2018; } \\
\text { Frank et al., 2019; } \\
\text { Zhang et al., } 2018\end{array}$ \\
\hline
\end{tabular}


TABLE 1 | Continued

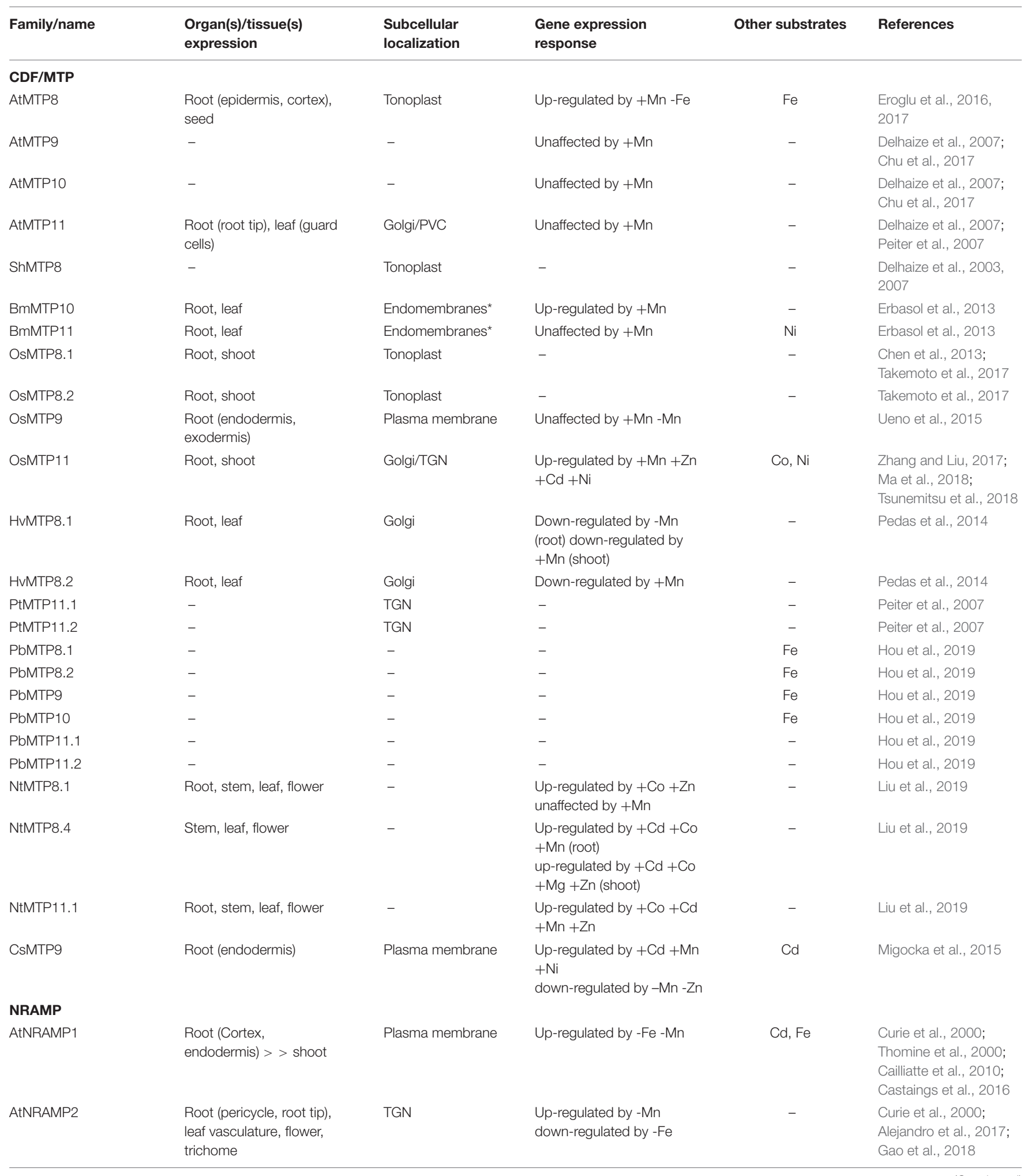


TABLE 1 | Continued

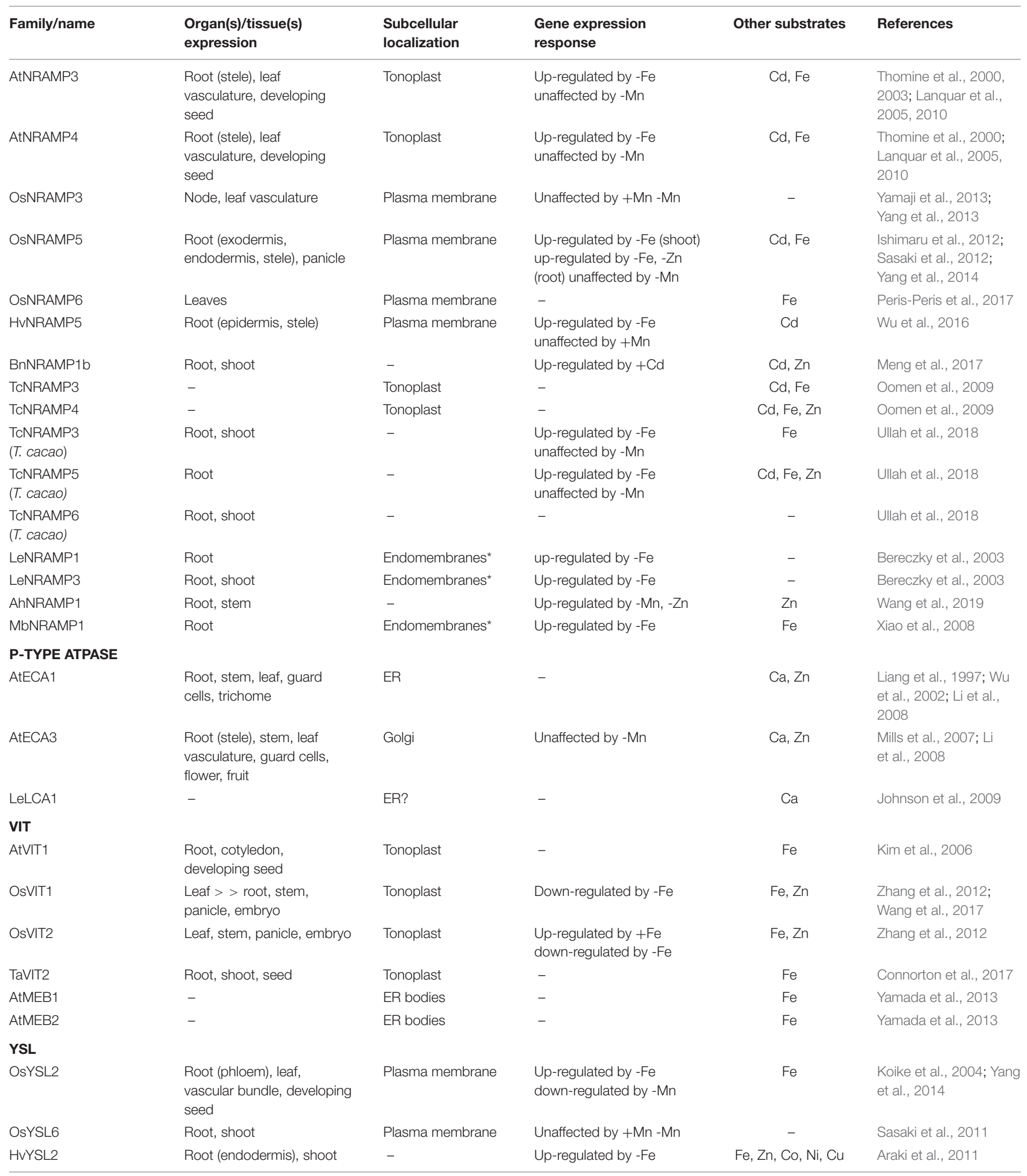


TABLE 1 | Continued

\begin{tabular}{|c|c|c|c|c|c|}
\hline Family/name & $\begin{array}{l}\text { Organ(s)/tissue(s) } \\
\text { expression }\end{array}$ & $\begin{array}{l}\text { Subcellular } \\
\text { localization }\end{array}$ & $\begin{array}{l}\text { Gene expression } \\
\text { response }\end{array}$ & Other substrates & References \\
\hline \multicolumn{6}{|l|}{ ZIP } \\
\hline AtIRT1 & $\begin{array}{l}\text { Root (epidermis, } \\
\text { cortex) }>>\text { shoot }\end{array}$ & Plasma membrane & Up-regulated by -Fe & $\mathrm{Fe}, \mathrm{Zn}, \mathrm{Co}, \mathrm{Ni}$ & $\begin{array}{l}\text { Korshunova et al., } \\
\text { 1999; Curie et al., } \\
\text { 2000; Thomine et al., } \\
\text { 2000; Vert et al., } 2002\end{array}$ \\
\hline AtZIP1 & Root (stele), leaf vasculature & Tonoplast & $\begin{array}{l}\text { Up-regulated by -Fe -Zn } \\
\text { (root) up-regulated by -Mn } \\
\text { (shoot) down-regulated by } \\
\text {-Zn (shoot) }\end{array}$ & $\mathrm{Zn}$ & Milner et al., 2013 \\
\hline AtZIP2 & Root (stele) & Plasma membrane & Down-regulated by -Fe -Mn & $\mathrm{Zn}$ & Milner et al., 2013 \\
\hline AtZIP5 & Root, shoot & - & - & - & Milner et al., 2013 \\
\hline AtZIP6 & Root, shoot & - & - & - & Milner et al., 2013 \\
\hline AtZIP7 & Shoot $>>$ root & - & - & $\mathrm{Fe}, \mathrm{Zn}$ & $\begin{array}{l}\text { Milner et al., 2013; Fu } \\
\text { et al., } 2017\end{array}$ \\
\hline AtZIP9 & Root, shoot & - & - & - & Milner et al., 2013 \\
\hline HvIRT1 & $\begin{array}{l}\text { Root (epidermis, cortex }{ }^{\star \star} \text {, } \\
\text { endodermis }{ }^{\star \star}, \text { pericycle), } \\
\text { seed }\end{array}$ & Plasma membrane & Up-regulated by -Fe, -Mn & $\mathrm{Fe}, \mathrm{Zn}$ & $\begin{array}{l}\text { Pedas et al., 2008; } \\
\text { Long et al., } 2018\end{array}$ \\
\hline LelRT1 & Root, flower & - & - & $\mathrm{Cd}, \mathrm{Fe}, \mathrm{Zn}$ & Eckhardt et al., 2001 \\
\hline LelRT2 & Root & - & - & $\mathrm{Cd}, \mathrm{Fe}, \mathrm{Zn}$ & Eckhardt et al., 2001 \\
\hline MtZIP4 & $\operatorname{Root}^{\star \star \star}$, leaf & - & $\begin{array}{l}\text { Down-regulated by -Fe }-\mathrm{Mn} \\
\text { up-regulated by }+\mathrm{Zn}\end{array}$ & - & $\begin{array}{l}\text { López-Millán et al., } \\
2004\end{array}$ \\
\hline MtZIP7 & Leaf & - & Unaffected by $-\mathrm{Mn}$ & - & $\begin{array}{l}\text { López-Millán et al., } \\
2004\end{array}$ \\
\hline PtIRT1 & Root, leaf & - & Down-regulated by -Mn & $\mathrm{Fe}, \mathrm{Zn}$ & Fu et al., 2017 \\
\hline
\end{tabular}

+ excess, - deficiency, ${ }^{*}$ in yeast cells, ${ }^{* *}$ only under $+\mathrm{Fe}$, ${ }^{* * *}$ only under $+\mathrm{Zn}$.

(Henriques, 2004; Hebbern et al., 2009; Alejandro et al., 2017), as well as higher susceptibility to pathogen infections (Heckman et al., 2003; Heine et al., 2011), imbalance in plant water relations (Ohki, 1985; Hebbern et al., 2009), and decreased tolerance to low temperatures (Ihnatowicz et al., 2014; Stoltz and Wallenhammar, 2014). Mn deficiency leads to a reduced number of Mn-complexes in the PSII core, which causes the destabilization and disintegration of PSII complexes that lowers the net photosynthesis rate (Schmidt et al., 2016). Besides, the disintegration of PSII complexes directly affects the thylakoid structure and promotes chlorophyll degradation leading to the development of characteristic interveinal leaf chlorosis (Papadakis et al., 2007). Due to the low phloem mobility of Mn (Ferrandon and Chamel, 1988; Li et al., 2017), typical symptoms of Mn deficiency first develop in younger leaves. Pale mottled leaves and interveinal chlorosis are the most visible symptoms of the disorder (Schmidt et al., 2016). Under severe Mn deficiency, leaves may also develop gray speck symptoms, which are characterized by brownish or necrotic spots (Broadley et al., 2012). It has been proposed that necrotic spots are a consequence of an increase in free oxygen radicals in damaged chloroplasts and a decrease in MnSOD activity (Broadley et al., 2012; Hajiboland, 2012). Similar responses have been described in Chlamydomonas, where a decrease in photosynthesis and mitochondrial MnSOD function was observed under Mndeficient conditions (Allen et al., 2007). However, Mn-starved Arabidopsis seedlings showed a decrease in net photosynthesis while there was no loss of MnSOD activity (Lanquar et al., 2010). This suggests that the use of the cellular Mn pool for Mn-requiring metabolic reactions under low Mn conditions is variable among photosynthetic organisms.

In roots, an increase in the frequency of root hairs can be observed under Mn deficiency (Yang et al., 2008). If the deficiency becomes more severe, root tips may develop serious necrosis (Yamaji et al., 2013).

Toxic Mn concentrations are highly dependent on plant species and genotypes (Husted et al., 2009; Broadley et al., 2012; Fernando and Lynch, 2015). Excess Mn may be stored in vacuoles (Dučić and Polle, 2007; Dou et al., 2009), cell walls (Führs et al., 2010), and distributed to different leaf tissues (Fernando et al., 2006a,b). Also, Mn can be chelated in Mn-P complexes in trichomes (McNear and Küpper, 2014; Blamey et al., 2015) and complexed by organic acids in leaves (Lambers et al., 2015). Therefore, it is likely that differences between plant species lie in the cellular distribution and speciation of $\mathrm{Mn}$, dominated by complexes with malate or citrate (Fernando et al., 2010). At the molecular level, excessive $\mathrm{Mn}$ can prevent the uptake and translocation of other essential elements such as $\mathrm{Ca}, \mathrm{Mg}$, Fe, and P (Alam et al., 2005; St.Clair and Lynch, 2005; Blamey et al., 2015; Lešková et al., 2017), inhibit chlorophyll biosynthesis (Clairmont et al., 1986; Subrahmanyam and Rathore, 2001), cause a decline in the photosynthetic rate (Nable et al., 1988; Amao and Ohashi, 2008), reduce the meristematic cell division in roots by inhibiting auxin biosynthesis (Morgan et al., 1966; 
Zhao et al., 2017), and lead to an increase in the accumulation of oxidized Mn and oxidized phenolic compounds in the apoplast (Fecht-Christoffers et al., 2006).

The symptoms of $\mathrm{Mn}$ toxicity vary widely among plant species, with chlorotic leaves and necrotic spots as the most common symptoms (Millaleo et al., 2010). Accordingly, Mn stress in plants has been explained by two main hypotheses based on either symplastic or apoplastic processes (Fernando and Lynch, 2015). The symplastic hypothesis proposes that Mn toxicity acts via photo-oxidative stress in the chloroplast that causes chlorosis. Conversely, in the apoplastic hypothesis, Mn stress damage is mainly due to the accumulation of Mn oxides, oxidized phenolic compounds, and ROS, in the cell wall, leading to necrosis. Necrotic spots have thus been associated with the accumulation and oxidation of Mn and of oxidized phenolic compounds, while chlorosis has been often attributed to Fe deficiency induced by high Mn. Surprisingly, necrotic spots are high in Mn and appear first on older leaves, whereas in chlorotic areas no $\mathrm{Mn}$ accumulation can be observed. It is hence conceivable that the mechanism resulting in necrotic spots differs from that which causes chlorosis.

Several lines of evidence suggest that the early target of Mn toxicity is the photosynthetic process (Millaleo et al., 2010). In fact, plants exposed to Mn excess showed a decline in net photosynthesis rate and chlorophyll content (Li et al., 2010). Although in chloroplasts the occurrence of thylakoid swelling has been associated with the administration of excess Mn (Lidon et al., 2004; Doncheva et al., 2009), the target of Mn in these photosynthetic membranes is still unclear. It has been proposed that the oxidation of $\mathrm{Mn}$ in chloroplasts by light-activated chlorophyll generates ROS, and thereby damages chlorophyll (Panda et al., 1987; Baldisserotto et al., 2007). At the same time, Mn may substitute Mg in chlorophyll molecules or bind to ferredoxin in the thylakoid matrix, eventually destroying the ultrastructure of chloroplasts (Panda et al., 1987; Hauck et al., 2003). Moreover, the lack of physiologically active Fe would be a secondary effect of Mn toxicity (Nian, 1989; Huang et al., 2016), which might block chlorophyll synthesis and the correct assembly of photosystem I (PSI) (Chereskin and Castelfranco, 1982; Cornah et al., 2002; Millaleo et al., 2013). Consequently, photoinhibition of PSII would likely be a late side effect of Mn exposure.

\section{MANGANESE DYNAMICS IN SOIL}

$\mathrm{Mn}$ is one of the most abundant and widely distributed metals in nature and comprises about $0.1 \%$ of the Earth's crust (Emsley, 2003). The element is found in minerals, combined with other elements such as oxygen, sulfur, carbon, silicon, and chlorine (Turekian and Wedepohl, 1961). Mn can exist in 11 oxidation states, ranging from -3 to +7 , but in soils, $\mathrm{Mn}$ is mainly present as +2 (e.g., $\mathrm{Mn}^{2+}$ ), +3 (e.g., $\mathrm{Mn}_{2} \mathrm{O}_{3}$ ) and +4 (e.g., $\mathrm{MnO}_{2}$ ). Availability of Mn to plants depends on its oxidation state: $\mathrm{Mn}^{2+}$ is the only plant-available form and can be readily transported into root cells and translocated to the shoot, whereas the oxidized species $\mathrm{Mn}(\mathrm{III})$ and $\mathrm{Mn}(\mathrm{IV})$ form insoluble oxides that rapidly sediment (Stumm and Morgan, 1996). Thus, Mn dynamics in soils are mostly represented by the concept of a balance between soluble $\mathrm{Mn}^{2+}$ and insoluble $\mathrm{Mn}$ oxides $\left(\mathrm{MnO}_{x}\right)$.

Mn deficiency in plants is particularly prevalent in alkaline soils, in which the oxidization of $\mathrm{Mn}^{2+}$ to unavailable $\mathrm{MnO}_{x}$ is favored. Such soils are common in the northern part of Europe, the UK, USA, China, and in southern Australia (Husted et al., 2009; George et al., 2014). In addition to $\mathrm{pH}$, the oxygen level $\left(\mathrm{pO}_{2}\right)$ in soil and soil microorganisms are also relevant factors of $\mathrm{Mn}$ dynamics in soils. Beside this, root exudates can modify the Mn availability in the rhizosphere. The Mn redox status in soils involves primarily the competition of soluble highly mobile oxidants, such as molecular $\mathrm{O}_{2}$, and soluble reducing organic molecules, derived from soil organic matter and biological sources. In aerobic soils, due to the high mobility and redox potential of $\mathrm{O}_{2}$, Mn oxidation is favored rather than reduction of $\mathrm{MnO}_{x}$ by microorganisms (Lovely, 1995). By contrast, waterlogging causes a reduction of $\mathrm{MnO}_{x}$ most likely by decreasing the $\mathrm{O}_{2}$ concentration, leading to an increase of plant-available $\mathrm{Mn}^{2+}$ in soil solution up to toxic levels (Khabaz-Saberi et al., 2006).

However, it has been proposed that the oxidation of $\mathrm{Mn}^{2+}$ in environments with abundant $\mathrm{O}_{2}$ is sluggish, particularly in the absence of biological catalysts, and that the oxidation of $\mathrm{Mn}^{2+}$ in soil is carried out predominantly by microorganisms (Sparrow and Uren, 2014). Indeed, microorganisms can catalyze $\mathrm{Mn}^{2+}$ oxidation in order of $10^{3}$ times faster than abiotic oxidation (Morgan, 2005). Some microorganisms produce enzymes which directly oxidize $\mathrm{Mn}^{2+}$, or produce extracellular superoxide leading to the production of insoluble $\mathrm{MnO}_{x}$ (Hansel et al., 2012; Zhang et al., 2014). Conversely, other microorganisms can reduce $\mathrm{MnO}_{x}$ and thereby increase $\mathrm{Mn}$ availability for plant uptake (Rengel, 2015). Also, environmental conditions (temperature, humidity) affect soil Mn availability by modulating the activity of Mn-oxidizing microorganisms (Sparrow and Uren, 2014). Therefore, the population of Mn-oxidizing and Mn-reducing microorganisms is a key factor in the availability of soil Mn for plant uptake.

Another important factor of Mn dynamics in soils is the exudation of protons $\left(\mathrm{H}^{+}\right)$, carboxylates, and enzymes by plant roots. Proton exudation increases the $\mathrm{Mn}$ availability in the rhizosphere by exchanging Mn that is immobilized by negatively charged organic matter and clay minerals, and also by lowering the $\mathrm{pH}$ of alkaline soils (Rengel, 2015). Mn uptake by some Mnhyperaccumlators, such as Phytolacca species, is based on a strong rhizosphere acidification (Lambers et al., 2015). Noteworthy, Mn availability is also increased by root exudation of carboxylates which chelate $\mathrm{Mn}$ and reduce $\mathrm{Mn}(\mathrm{IV})$ to $\mathrm{Mn}^{2+}$ in either acidic or alkaline soils (Jauregui and Reisenauer, 1982; Gherardi and Rengel, 2004).

Phytate (inositol hexaphosphate) is generally the dominant form of organic $\mathrm{P}$ in soils and has the potential to complex $\mathrm{Mn}^{2+}$ and other divalent cations. Exudation of phytases, which catalyze the degradation of phytate thus increases the Mn availability by releasing $\mathrm{Mn}^{2+}$ (George et al., 2014).

The release of carboxylates into the rhizosphere is a mechanism for the acquisition of not only $\mathrm{Mn}$, but in particular 
of P. Carboxylates mobilize $\mathrm{P}$ absorbed to Fe/Al hydroxides by ligand exchange, especially under low $\mathrm{P}$ availability (Nuruzzaman et al., 2006). By contrast, elevated levels of soil-P lead to a reduction of carboxylate and phytase exudation, in turn decreasing $\mathrm{Mn}^{2+}$ acquisition (Lambers et al., 2015; Giles et al., 2017). However, hydroponic experiments in barley, where most likely no $\mathrm{Mn}-\mathrm{P}$ complexes were formed, have also shown a decrease in Mn uptake under elevated P supply (Pedas et al., 2011). Hence, it has been proposed that there is a competition between $\mathrm{Mn}^{2+}$ and $\mathrm{P}$ during Mn uptake.

\section{MANGANESE TRANSPORT PROTEINS IN PLANTS}

As mentioned above, reduced $\mathrm{Mn}\left(\mathrm{Mn}^{2+}\right)$ is the only available form for plants. To maintain an optimal supply, acquisition from the rhizosphere and distribution of $\mathrm{Mn}$ have to be regulated. One of the most important mechanisms to regulate the acquisition from the soil is the uptake by specific transporters into root cells (Figure 1). Once Mn reaches the symplast, the main pathways for the translocation and distribution of $\mathrm{Mn}$ in the whole plant involve transport toward and into the xylem, transfer to the phloem, and translocation to and between the different tissues. However, most of the Mn transporters and mechanisms required for Mn loading into the xylem of the root stele, for loading $\mathrm{Mn}$ into the phloem, and for $\mathrm{Mn}$ transport into the plant cell in shoots have not been identified yet. Interestingly, the mobility of $\mathrm{Mn}$ in the phloem is supposed to be low (Li et al., 2017), but there is evidence that a small amount of Mn may be recycled via the phloem. In fact, it has been reported that after application of ${ }^{52} \mathrm{Mn}$ to a cut barley leaf, radioactivity was detectable in the discrimination center of the shoot, in other leaves, as also in root tips (Tsukamoto et al., 2006). These results suggested that ${ }^{52} \mathrm{Mn}$ was transported by unknown transporters with low affinity.

An intriguing property of $\mathrm{Mn}$ transport across membranes is that most of the proteins that transport $\mathrm{Mn}$ are not specific for the metal. Plant $\mathrm{Mn}^{2+}$ transporters can transport, to varying extent, other divalent cations, such as $\mathrm{Fe}^{2+}, \mathrm{Zn}^{2+}, \mathrm{Cu}^{2+}$, $\mathrm{Cd}^{2+}, \mathrm{Ca}^{2+}, \mathrm{Co}^{2+}$, and $\mathrm{Ni}^{2+}$. The physiological relevance of this low specificity needs further investigations, including the modification of specificity. For instance, in the $\mathrm{Mn} / \mathrm{Fe}$ transporter AtMTP8, Fe transport activity was inhibited by introducing point mutations in different Fe-binding domains without affecting its $\mathrm{Mn}^{2+}$ transport capability (Chu et al., 2017).

Diverse families of transport proteins are known to be components of the $\mathrm{Mn}$ homeostatic network in plants and can be classified into importers and exporters. Importers translocate $\mathrm{Mn}$ from the extracellular space or from internal compartments into the cytosol, whereas exporters are responsible for the exclusion of $\mathrm{Mn}$ out of the cytosol into intracellular compartments or into the apoplast. The Natural Resistance Associated Macrophage Protein (NRAMP) family, the ZincRegulated Transporter/Iron-Regulated Transporter (ZRT/IRT)related Protein (ZIP) family, and the Yellow Stripe-Like (YSL) family have members involved in the transport of $\mathrm{Mn}^{2+}$ into the cytosol. In contrast, the Cation Diffusion Facilitator/Metal Transport Protein (CDF/MTP) family, the Vacuolar Iron Transporter (VIT) family, the $\mathrm{Ca}^{2+} /$ Cation Antiporter (CaCA) superfamily, the Bivalent Cation Transporter (BICAT) family, and the $\mathrm{P}_{2 A}$-type ATPase family have members involved in the transport of $\mathrm{Mn}^{2+}$ out of the cytosol. Figure 1 shows the tissue specificity and subcellular localization of Mn transport proteins in roots of Arabidopsis, rice, and other plant species. Genes encoding encoding Mn transport proteins in aerial parts of the plant species are depicted in Figure 2, and the subcellular localization of these proteins is displayed in Figure 3. The NRAMP family has been characterized in a number of species including bacteria, fungi, plants, and animals. These proteins act as metal $/ \mathrm{H}^{+}$symporters and are capable of transporting divalent metal cations $\left(\mathrm{Fe}^{2+}, \mathrm{Mn}^{2+}, \mathrm{Zn}^{2+}, \mathrm{Cd}^{2+}, \mathrm{Co}^{2+}, \mathrm{Ni}^{2+}, \mathrm{Cu}^{2+}\right)$ into the cytosol (Nevo and Nelson, 2006), with the exceptions of OsNRAMP4 (syn. OsNrat1), that transports the trivalent cation $\mathrm{Al}^{3+}$ (Xia et al., 2010; Li et al., 2014), and OsNRAMP1, that appears to mediate also As(III) transport (Tiwari et al., 2014).

The ZIP transporters have been found widely in bacteria, fungi, plants, and animals and are predicted to be involved in $\mathrm{Fe}^{2+}, \mathrm{Zn}^{2+}, \mathrm{Cd}^{2+}, \mathrm{Co}^{2+}, \mathrm{Cu}^{2+}$, and $\mathrm{Mn}^{2+}$ transport. They have 8 transmembrane domains (TMD) with extracellular Nand C-termini and a cytosolic histidine-rich loop (Guerinot, 2000). YSL transporters are related to the OligoPeptide Transporter (OPT) family and are exclusively found in plants, bacteria, fungi, and archaea. Members of the YSL family are predicted to transport metals $\left(\mathrm{Mn}^{2+}, \mathrm{Zn}^{2+}, \mathrm{Cu}^{2+}\right.$, $\mathrm{Ni}^{2+}, \mathrm{Cd}^{2+}, \mathrm{Fe}^{2+}$ ) complexed to non-proteinogenic amino acids, such as nicotianamine (NA) or phytosiderophores (PS) (Schaaf et al., 2004).

The CDF family has members in all organisms. Most CDFs are $\mathrm{Metal}^{2+} / \mathrm{H}^{+}\left(\mathrm{K}^{+}\right)$antiporters and mediate the efflux of $\mathrm{Zn}^{2+}$, $\mathrm{Co}^{2+}, \mathrm{Fe}^{2+}, \mathrm{Cd}^{2+}, \mathrm{Ni}^{2+}$, and/or $\mathrm{Mn}^{2+}$. Most of them have six TMDs with histidine-rich regions at their cytosolic $\mathrm{N}$ - and/or C-terminus and additionally between the 4th and 5th TMD. Based on phylogenetic relationships, the CDF family can be classified, corresponding to the main transported metal, into three major subgroups: Zn-CDFs, Fe/Zn-CDFs, and Mn-CDFs (Montanini et al., 2007).

BICAT proteins, also denominated Photosynthesis-Affected Mutant71 (PAM71) or Chloroplast Manganese Transporter (CMT) proteins, belong to the Uncharacterized Protein Family 0016 (UPF0016), which represents a new family of cation transporters present in all eukaryotes and prokaryotes, except in Lactobacillales and Bacillales (Demaegd et al., 2013, 2014; Hoecker et al., 2017). The protein structure of the plant homologs is characterized by two clusters of three transmembrane domains separated by a central loop. BICAT proteins act as $\mathrm{Mn}^{2+}$ and $\mathrm{Ca}^{2+}$ transporters (Hoecker et al., 2017; Frank et al., 2019).

CaCA transporters are present in all kingdoms of life and have a conserved core structure of ten transmembrane domains and two conserved $\alpha$-repeat regions containing acidic amino acids (Pittman and Hirschi, 2016). In particular, the Cation/ $\mathrm{Ca}^{2+}$ exchanger (CCX) and the $\mathrm{H}^{+} /$Cation exchanger (CAX) families, which are both members of the CaCA superfamily, are present within all plants. 
A Arabidopsis thaliana

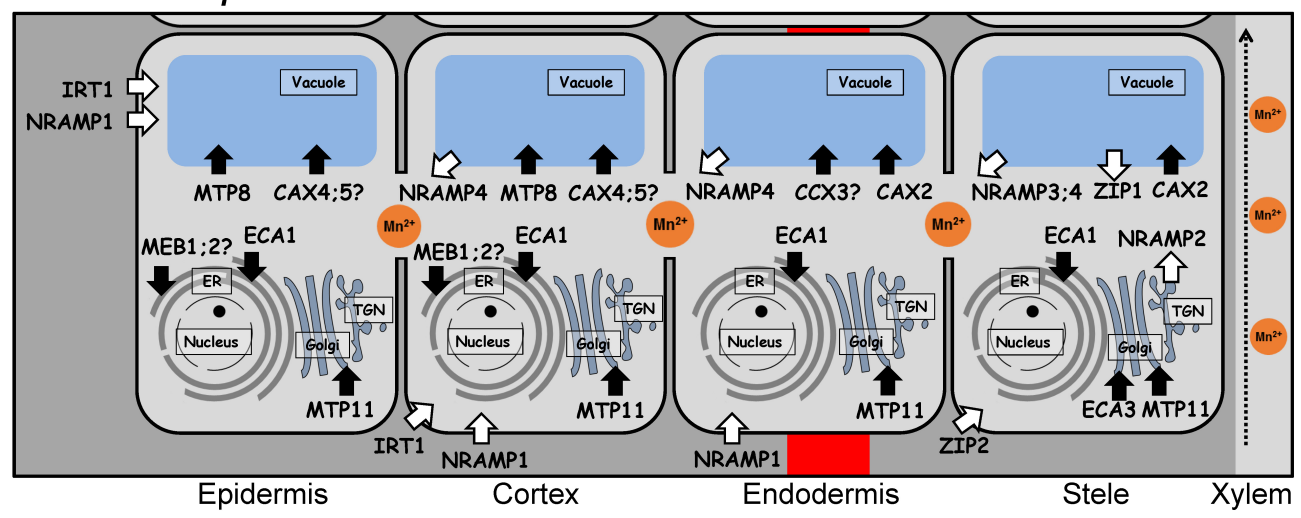

B Oryza sativa

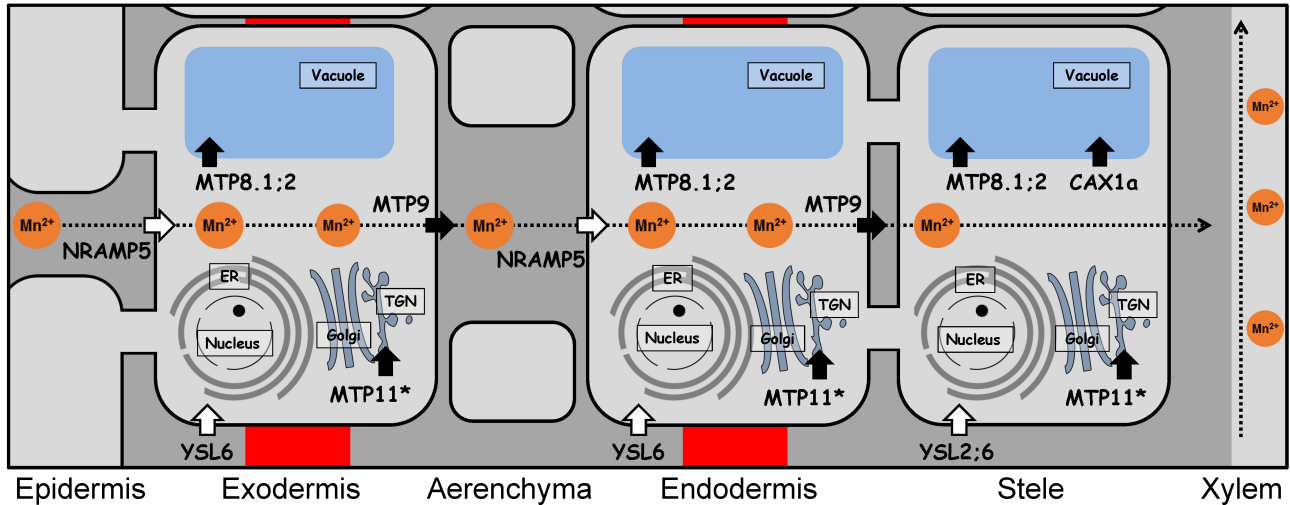

c Other plant species

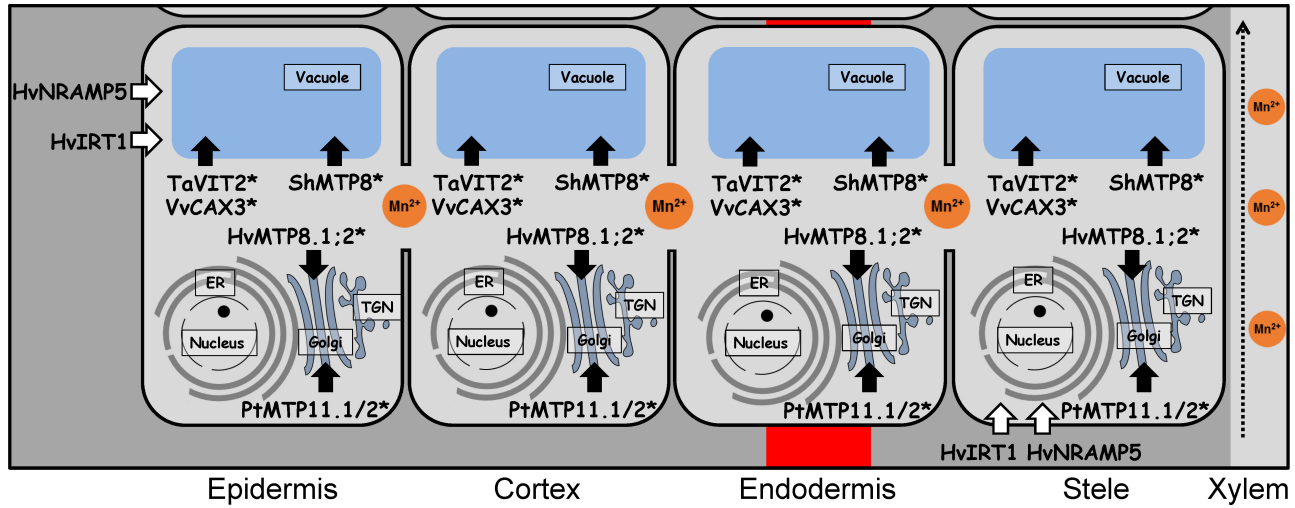

FIGURE 1 | Tissue specificity and subcellular localization of Mn transport proteins in roots of different plant species. (A) Mn transport proteins in epidermis, endodermis, cortex, and stele (including pericycle) of Arabidopsis roots. (B) Mn transport proteins in exodermis, endodermis, and stele of rice roots. Radial transport of $\mathrm{Mn}^{2+}$ is carried out by OsNRAMP5 and OsMTP9, which are polarly localized transporters at both the exodermis and the endodermis, providing a unidirectional flux of $\mathrm{Mn}$ from the soil to the stele (indicated as dashed arrow). (C) Mn transport proteins in epidermis, endodermis, cortex, and stele of roots of other plant species. (A-C) White arrows indicate import into the cytosol, black arrows indicate export out of the cytosol. Transport proteins with yet unknown root tissue specificity are marked by asterisks. Proteins which subcellular localization only shown in yeast but not in plants are indicated by a question mark. Hv, Hordeum vulgare; Pt, Populus trichocarpa; Sh, Stylosanthes hamata; Ta, Triticum aestivum; Vv, Vitis vinifera.

VIT transporters are found in plants, fungi, and bacteria, but are absent in animals. Members of the VIT family in plants share a high degree of sequence similarity and most of them are capable to transport $\mathrm{Fe}^{2+}$ in addition to $\mathrm{Mn}^{2+}$, but their biological functions have been poorly investigated (Cao, 2019).

Plant P-type $\mathrm{Ca}^{2+}$-ATPases are divided into two groups, 2A and $2 \mathrm{~B}$, whereby the first one does not contain an $\mathrm{N}$-terminal 

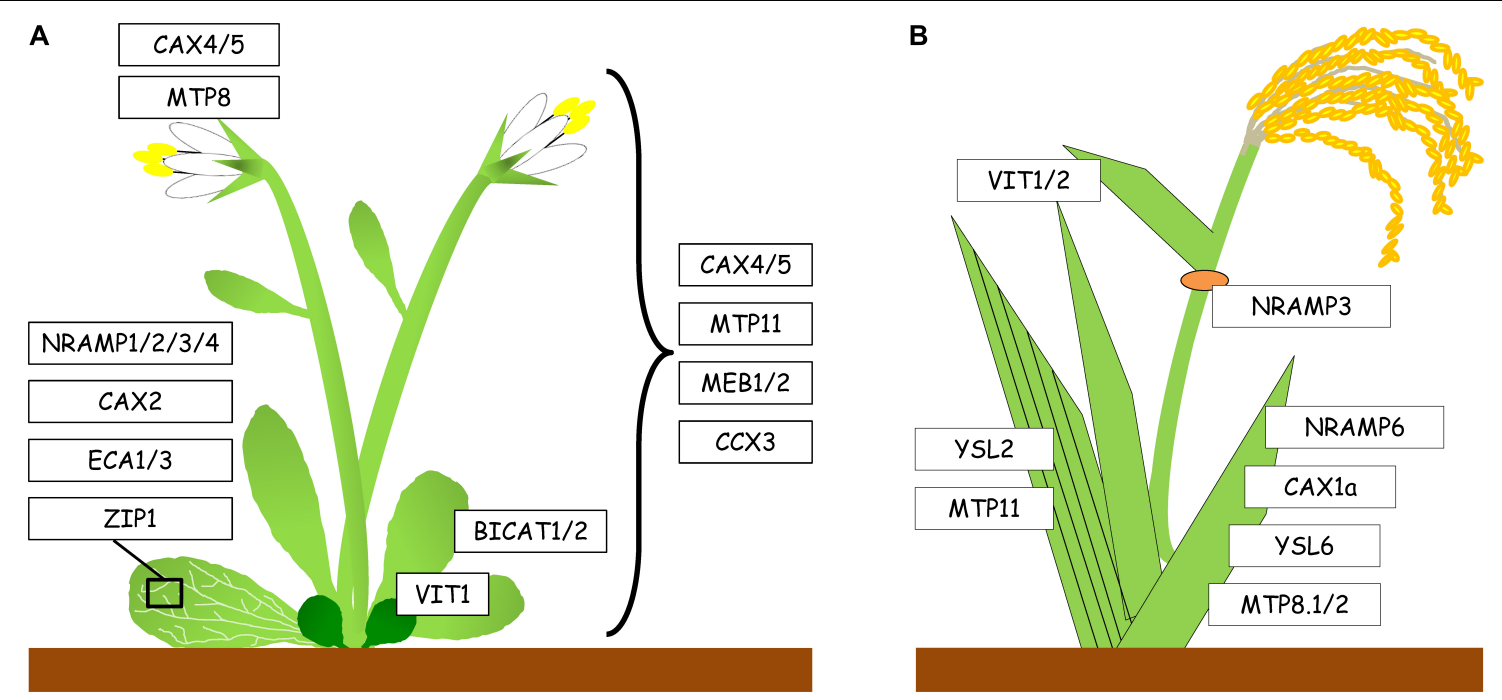

FIGURE 2 | Expression of genes encoding Mn transport proteins in aerial parts of Arabidopsis and rice. (A) Mn transport proteins in shoots of Arabidopsis. Transporters listed on the left are expressed in the vasculature of leaves, transporters listed on the right are expressed throughout the above-ground tissues of the plant. In vegetative tissues, AtVIT1 is only expressed in cotyledons. (B) Mn transport proteins in shoots of rice. OsMTP11 and OsYSL2 are expressed in the vasculature. OsNRAMP3 is expressed in the first node (orange). OsYSL6 and OsMTP8.1/2 are expressed in older leaves, whereas expression of OsVIT1/2 is more pronounced in younger leaves.

autoinhibitory domain (Johnson et al., 2009). Those $\mathrm{P}_{2 \mathrm{~A}}$-type $\mathrm{Ca}^{2+}$-ATPases have also a role in $\mathrm{Mn}^{2+}$ transport.

\section{MANGANESE UPTAKE FROM THE SOIL AND TRANSLOCATION TO THE SHOOT}

Despite the importance of Mn in plant physiology, our knowledge of systems mediating Mn uptake followed by translocation from the roots to the shoot is limited. This is mainly due to the lack of information about the expression and subcellular localization of $\mathrm{Mn}$ transporters in most plants. In fact, only few Mn transporters involved in uptake and root radial transport have been identified so far. Uptake of $\mathrm{Mn}^{2+}$ has been assumed to be mediated by plasma membrane $\mathrm{Ca}^{2+}$ channels, which are generally permeable to $\mathrm{Mn}^{2+}$ (Wymer et al., 1997; White et al., 2002). However, this is likely to be a minor $\mathrm{Mn}^{2+}$ uptake pathway due to its competition with $\mathrm{Ca}^{2+}$, only relevant when $\mathrm{Mn}^{2+}$ is present in high concentrations. However, in soil, $\mathrm{Mn}^{2+}$ is usually far less abundant than $\mathrm{Ca}^{2+}$ (Broadley et al., 2012). Since this assumption, few $\mathrm{Mn}$ transporters have been identified mainly in A. thaliana and rice. Their tissue-specific localizations in roots are shown in Figure 1A for Arabidopsis, in Figure 1B for rice, and in Figure 1C for other plant species including barley, wheat, tomato, poplar, and grapevine.

In Arabidopsis, there is plenty of evidence that $\mathrm{Mn}^{2+}$ uptake is mainly mediated by AtNRAMP1 (Figure 1A), which is localized in the plasma membrane of epidermis and cortex cells in roots, and less in vascular tissues of young leaves (Cailliatte et al., 2010; Castaings et al., 2016). Under Mn-deficient conditions, the expression of AtNRAMP1 is moderately up-regulated, and nramp1 knockout mutants accumulate less $\mathrm{Mn}$ in shoots under
Mn deficiency, which points to a function of this protein as a high-affinity $\mathrm{Mn}^{2+}$ uptake transporter (Cailliatte et al., 2010). NRAMP1 orthologs in cacao, rapeseed, and peanut are also expressed in roots and complement a Mn uptake-deficient yeast strain, smf1, lacking a Mn transporter located in the plasma membrane (Meng et al., 2017; Ullah et al., 2018; Wang et al., 2019). In addition, active $\mathrm{Mn}^{2+}$ uptake may be accomplished by the ZIP transporter AtIRT1 (Castaings et al., 2016), that is considered as the major $\mathrm{Fe}$ uptake transporter of dicots. However, AtIRT1 is not strongly selective for $\mathrm{Fe}^{2+}$, but also transports $\mathrm{Zn}^{2+}, \mathrm{Cu}^{2+}, \mathrm{Co}^{2+}, \mathrm{Ni}^{2+}$, and $\mathrm{Mn}^{2+}$ (Korshunova et al., 1999). IRT1 orthologs expressed in roots have also been identified in tomato and trifoliate orange, but their function in $\mathrm{Mn}^{2+}$ uptake remains to be confirmed (Eckhardt et al., 2001; Fu et al., 2017). Furthermore, two ZIP transporters expressed in the root stele are described to be involved in root-to-shoot translocation of Mn in Arabidopsis (Milner et al., 2013). AtZIP1 is a transporter localized to the tonoplast and probably involved in remobilizing $\mathrm{Mn}^{2+}$ from vacuoles to the cytosol in root stele cells, whereas AtZIP2 is localized to the plasma membrane and may mediate $\mathrm{Mn}^{2+}$ uptake into cells of the root stele. Other $\mathrm{Mn}^{2+}$ transporters of the AtZIP family are also expressed in roots, but their function in $\mathrm{Mn}^{2+}$ uptake and remobilization is still unknown (Milner et al., 2013).

In comparison with other plant species, in rice, transporters involved in uptake, xylem loading, and root-to-shoot translocation of $\mathrm{Mn}$ have been functionally characterized more extensively (Shao et al., 2017). The first $\mathrm{Mn}^{2+}$ transporter identified in rice roots was OsNRAMP5, which contributes to $\mathrm{Mn}^{2+}$ uptake and translocation (Sasaki et al., 2012). Further investigations showed that $\mathrm{Mn}^{2+}$ uptake and translocation works in conjunction with another transporter next to OsNRAMP5, 


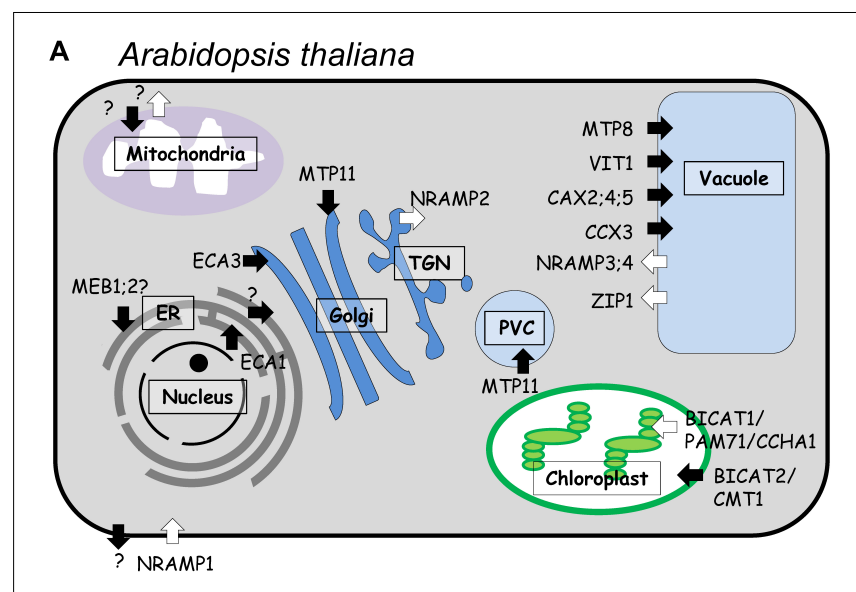

B Oryza sativa

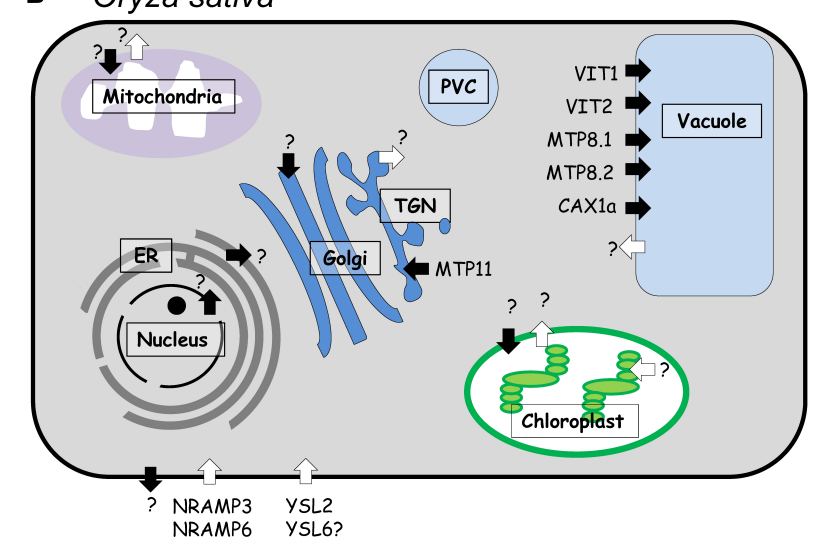

\section{Other plant species}

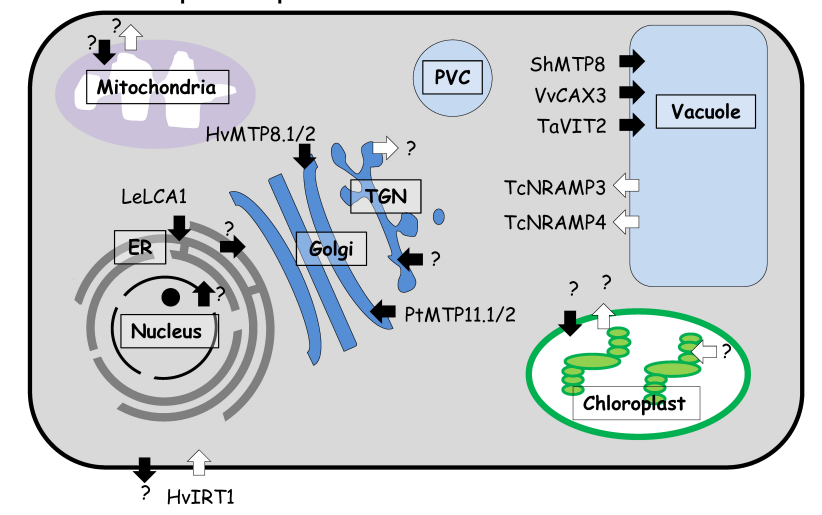

FIGURE 3 | Subcellular localization of Mn transport proteins in aerial parts of different plant species. (A) Arabidopsis, (B) rice, and (C) other species. White arrows represent import into the cytosol, black arrows represent export from the cytosol. Transport pathways with uncharacterized Mn transporters are indicated by a question mark. Hv, Hordeum vulgare; Le, Lycopersicum esculentum (syn. Solanum lycopersicum); Pt, Populus trichocarpa; Sh, Stylosanthes hamata; Ta, Triticum aestivum; Vv, Vitis vinifera.

namely OsMTP9 (Ueno et al., 2015). OsNRAMP5, localized to the plasma membrane of the distal side of the exo- and endodermis was shown to be responsible for the import of $\mathrm{Mn}^{2+}$ from the soil solution (Figure 1B). Subsequently, OsMTP9, localized to the plasma membrane of the proximal side of these cell layers, mediates the export of $\mathrm{Mn}^{2+}$ into the stele (Sasaki et al., 2012; Ueno et al., 2015). Knockout of either OsMTP9 or OsNRAMP5 significantly decreased $\mathrm{Mn}^{2+}$ uptake and rootto-shoot translocation, indicating that both transporters are responsible for transporting $\mathrm{Mn}^{2+}$ from the soil to the xylem.

Interestingly, in barley, the plasma membrane transporter HvIRT1 is implicated in the uptake and translocation of $\mathrm{Mn}^{2+}$, but not $\mathrm{Fe}^{2+}$ (Long et al., 2018). HvIRT1 is constitutively expressed in cells of the epidermis and in pericycle funder cells (Figure 1C), but under Mn deficiency, its expression is extended to the entire pericycle and the cortex. In hvirt1 RNAi lines, a reduced shoot Mn concentration was observed without changes in Fe or $\mathrm{Zn}$ concentrations. Barley is characterized as a strategy II plant species that requires HvYSL transporters for the uptake of $\mathrm{Fe}^{3+}$ complexed with phytosiderophores (PS) (Araki et al., 2011). Therefore, the Fe transport function of HvIRT1 has become redundant because $\mathrm{Fe}$ is acquired via strategy II processes. Although HvIRT1 may transport Fe in yeast (Pedas et al., 2008), HvIRT1 plays actually a key role in uptake and root-to-shoot translocation of Mn rather than Fe. HvNRAMP5 is another Mn transporter localized to the plasma membranes of cells in root tips of barley (Wu et al., 2016). In contrast to $H v I R T 1$, its expression is slightly upregulated by Fe deficiency, but not by Mn deficiency. Since HvIRT1 is up-regulated by Mn deficiency and HvNRAMP5 is constitutively expressed in roots (Wu et al., 2016), both transporters may play different roles. Therefore, it has been suggested that HvNRAMP5 may confer constitutive $\mathrm{Mn}^{2+}$ uptake, while HvIRT1 plays a role in $\mathrm{Mn}^{2+}$ uptake only under Mn-deficient conditions (Wu et al., 2016). The barley transporter HvYSL2 appears to mediate the transport of PS complexes with metals, including Mn, in the endodermis, and it may thus be involved in the transport of minerals from the cortex to the pericycle (Araki et al., 2011). However, further analyses of HvYSL2 are required to fully understand its biological role in barley.

Once $\mathrm{Mn}$ has been absorbed by the root, it needs to be translocated to the shoot. To date, the molecular basis of xylem loading of $\mathrm{Mn}$ is still unclear, and there is no clear evidence of which Mn complex is required to translocate Mn to the shoot via the xylem. Nevertheless, transporters of the YSL family may be involved in Mn translocation. In fact, during senescence, Mn concentration decreased in Arabidopsis wild type leaves, whereas no change was observed in the ysllysl3 double mutant (Waters et al., 2006). Hence, it has been proposed that both AtYSL1 and AtYSL3 are putative Mn-nicotianamine $\left(\mathrm{Mn}^{2+}-\mathrm{NA}\right)$ transporters, but so far, there is no direct evidence supporting this hypothesis. In rice, $\mathrm{Mn}^{2+}$ is transferred by OsNRAMP3 from the xylem to the phloem at the basal node, followed by its distribution to young leaves, panicles and root tips (Yamaji et al., 2013). However, at high Mn availability, Mn is distributed to mature tissues. Therefore, in rice nodes OsNRAMP3 functions as a switch for Mn distribution, whereby the protein is activated or deactivated in response to fluctuating $\mathrm{Mn}$ concentrations (Figure 2B). Moreover, a rice YSL transporter, OsYSL2, was proposed to be implicated in long-distance transport and distribution of $\mathrm{Mn}$, since it may transport $\mathrm{Mn}^{2+}-\mathrm{NA}$, as well 
as $\mathrm{Fe}^{2+}$-NA complexes (Koike et al., 2004). Because OsYSL2 is localized in phloem companion cells, it is probably involved in phloem loading of $\mathrm{Mn}^{2+}$-NA (Ishimaru et al., 2010), although its exact role in rice needs to be further investigated.

\section{MANGANESE UPTAKE BY LEAF CELLS}

As described above, a number of plasma membrane transporters involved in $\mathrm{Mn}^{2+}$ import into the cytosol of root cells has been characterized. In contrast, the identity of $\mathrm{Mn}^{2+}$ transporters in the plasma membrane of leaf cells remains largely elusive. Recently, it has been reported that OsNRAMP6, which is expressed in shoots, is localized to the plasma membrane (Figure 3B) and functions as $\mathrm{Fe}$ and $\mathrm{Mn}^{2+}$ transporter when expressed in yeast (Peris-Peris et al., 2017). Interestingly, OsNRAMP6 rescued, to some extent, the growth of yeast strains mutated in SMF1 (plasma membrane $\mathrm{Mn}^{2+}$ transporter) or SMF2 $\left(\mathrm{Mn}^{2+}\right.$ transporter in intracellular vesicles) under Mn-limited conditions. In plants, OsNRAMP6 accumulated in vesicles in the vicinity of the plasma membrane. Whether these vesicles represent an anterograde or retrograde trafficking stage of OsNRAMP6, depending on the $\mathrm{Mn}^{2+}$ status, remains to be elucidated. Moreover, an OsNRAMP6 knock-out plant showed enhanced resistance to infection by the rice fungus $M$. oryzae and a reduced biomass compared to wild type plants (PerisPeris et al., 2017). Therefore, it is likely that OsNRAMP6 plays a role in regulating the $\mathrm{Mn}$ and/or Fe contents in infected tissues which would boost the expression of defense genes. Based on the decreased root and shoot biomass of the nramp6 mutant under non-stress conditions, it was hypothesized that OsNRAMP6 functions as a Mn uptake transporter. Future studies are needed to establish the importance of OsNRAMP6 in cellular $\mathrm{Mn}^{2+}$ uptake and plant growth.

A second mechanism for Mn uptake into leaf cells of rice may be conferred by the OsYSL6 transporter, which was described to transport $\mathrm{Mn}^{2+}$-NA complexes from the leaf apoplast to the symplast (Sasaki et al., 2011). OsYSL6 is expressed in roots and shoots, particularly in older leaves. Due to the ability of OsYSL6 to increase $\mathrm{Mn}^{2+}$ influx when expressed in the $\operatorname{smf1}$ yeast mutant, it is likely localized in the plasma membrane (Sasaki et al., 2011). ysl6 mutant plants accumulate high Mn concentrations in the apoplast of shoots and exhibit symptoms of Mn toxicity. Therefore, it is likely that OsYSL6 translocates $\mathrm{Mn}^{2+}$ from the apoplast to the symplast where it is sequestered under $\mathrm{Mn}$ excess. However, since its expression level remains unchanged under either Mn deficiency or excess, OsYSL6 may also act as a constitutive $\mathrm{Mn}$ importer in leaf cells.

\section{INTRACELLULAR TRANSPORT OF MANGANESE}

Once Mn has entered a plant cell, it must be moved to the appropriate location for the adequate supply of $\mathrm{Mn}$ dependent targets or for storage. $\mathrm{Mn}$ is present in all cellular compartments, including ER, Golgi apparatus, mitochondria, plastids, and peroxisomes, where it performs specific cellular functions (see section Functions of Manganese in Plants), whereas vacuoles can serve as a reservoir to regulate cellular Mn homeostasis. Consequently, cells contain a plethora of transporters that are responsible for the distribution of $\mathrm{Mn}$ to the different compartments. Figure 3 shows an overview of $\mathrm{Mn}$ transporters previously described in different plant species and their subcellular localization. To structure the description of these $\mathrm{Mn}$ transporters in the following sections, they are organized based on their demonstrated or putative subcellular localization.

\section{Vacuoles as Manganese Stores}

Vacuoles generally function as a primary compartment for metal internalization to avoid metal toxicity. In the case of Mn, vacuoles also serve as a temporal Mn storage pool for a proper distribution to other organelles, e.g., chloroplasts (Lanquar et al., 2010). Many transporters have been described to contribute to vacuolar Mn sequestration and unloading processes.

In the tropical legume Stylosanthes hamata, a plant tolerant to acidic soils in which high concentrations of plant-available $\mathrm{Mn}^{2+}$ can occur, the tonoplast-localized Mn transporter ShMTP8 was identified (Delhaize et al., 2003). This protein was the first characterized member of the Mn-CDF subgroup and is involved in Mn detoxification by sequestering Mn into vacuoles. Sequence analysis of ShMTP8 showed that this protein lacks the complete $\mathrm{N}$-terminal sequence and the histidine-rich loop common for members of the CDF family. When expressed in Arabidopsis, ShMTP8 conferred tolerance to Mn toxicity (Delhaize et al., 2003). In pear and tobacco, members of the Mn-CDF subclade have also been described as Mn transporters, but their subcellular localization and relevance in Mn homeostasis is unknown (Hou et al., 2019; Liu et al., 2019). In Arabidopsis, the Mn-CDF subclade of the CDF/MTP family has four members, AtMTP8 through AtMTP11 (Montanini et al., 2007). All of them were shown to transport $\mathrm{Mn}^{2+}$ in yeast (Chu et al., 2017), but so far, only AtMTP8 and AtMTP11 have been described in more detail (Figure 3A). AtMTP8 was characterized as $\mathrm{Mn}^{2+}$ and $\mathrm{Fe}^{2+}$ transporter localized in the tonoplast (Eroglu et al., 2016; Chu et al., 2017; Eroglu et al., 2017). AtMTP8 expression was specific to cells of the epidermis and the cortex in roots and strongly induced by Fe deficiency (Eroglu et al., 2016). Moreover, mtp8 mutants showed chlorosis and critically low Fe levels in shoots on media with limited Fe availability, if Mn was present in the medium. This further demonstrated a Mn-specific role of AtMTP8 during Fe limitation, which lies in the detoxification of Mn taken up by the non-specific Fe transporter AtIRT1. In accord with a function of AtMTP8 in Mn detoxification, growth of $m t p 8$ mutants was impaired by high Mn, and AtMTP8 expression was increased under excess $\mathrm{Mn}^{2+}$ supply (Eroglu et al., 2016). Besides its role in the Fe deficiency response, AtMTP8 plays a second role during seed development. An analysis of metal localization in the embryo by $\mu$ XRF tomography showed that AtMTP8 is responsible for the specific accumulation of $\mathrm{Mn}$ in subepidermal cells on the abaxial side of the cotyledons and in cortical cells of the hypocotyl (Chu et al., 2017; Eroglu et al., 2017). In mutant embryos lacking the vacuolar Fe/Mn transporter AtVIT1, AtMTP8 built up Fe hotspots in those AtMTP8-expressing 
cell types, suggesting that AtMTP8 transports Fe in addition to $\mathrm{Mn}$. This was supported by complementation of the $\mathrm{Fe}$ sensitive yeast strain $c c c 1$. An mtp8vit1 double mutant showed a homogeneous distribution of both metals in all cell types of the embryo, demonstrating that both are the primary transporters determining $\mathrm{Mn}$ and Fe allocation (Chu et al., 2017; Eroglu et al., 2017). $\mathrm{Mn}^{2+}$ transport and vacuolar localization were also demonstrated for MTP8 orthologs in rice (Figure 3B). OsMTP8.1 was highly expressed in older leaves, and it was induced and repressed by high and low $\mathrm{Mn}^{2+}$ levels, respectively (Chen et al., 2013). OsMTP8.2 was expressed in roots and shoots, and it showed lower expression levels than OsMTP8.1 (Takemoto et al., 2017). The mtp8.1mtp8.2 double mutant suffered from necrotic leaf blades. Since Mn concentrations were comparable to those in healthy wild type plants, it has been suggested that this phenotype was the result of an insufficient Mn sequestration in the double mutant. Unlike AtMTP8 in Arabidopsis, there is no evidence that OsMTP8.1 and OsMTP8.2 are able to transport Fe or that their transcript levels are increased upon Fe deficiency (Chen et al., 2013; Takemoto et al., 2017).

VIT proteins in plants are mainly Fe transporters (Cao, 2019). AtVIT1, the most-studied VIT transporter in Arabidopsis, was identified as a vacuolar $\mathrm{Fe}$ transporter that is responsible for the localization of Fe primarily to the provascular strands of the embryo in seeds (Kim et al., 2006). The ability of AtVIT1 to transport $\mathrm{Mn}^{2+}$ was shown by metal analysis of vacuoles from the Fe-sensitive yeast strain $c c c 1$ expressing AtVIT1 (Kim et al., 2006). Interestingly, seeds of a vit1 mutant showed a localization of Fe that coincided with the localization of $\mathrm{Mn}$ in the subepidermal cells on the abaxial side of the cotyledons and that was dependent on AtMTP8, as discussed above (Chu et al., 2017; Eroglu et al., 2017). VIT transporters of rice, OsVIT1 and OsVIT2, not only partially rescued the $\mathrm{Fe}^{2+}$-sensitive phenotype, but also the $\mathrm{Zn}^{2+}$-sensitive phenotypes of yeast mutant strains. Similar to AtVIT1, an analysis of vacuolar metal composition of these cells showed an increased accumulation of Mn (Zhang et al., 2012). Moreover, OsVIT1 and OsVIT2 were shown to be highly expressed in flag leaf blades and leaf sheath. Consistent with these results, decreased accumulation of $\mathrm{Fe}$ and $\mathrm{Zn}$ was observed in flag leaves of osvit1 and osvit2 mutants. However, both mutants showed no significant change of $\mathrm{Mn}$ in these tissues or in grains (Zhang et al., 2012). These results suggest that OsVIT1 and OsVIT2 may function primarily in flag leaves to mediate vacuolar sequestration of $\mathrm{Fe}$ and $\mathrm{Zn}$. Moreover, the $\mathrm{Fe}$ and $\mathrm{Zn}$ accumulation in seeds and the decrease of those metals in flag leaves (the source organ) of osvit1 and osvit2 mutants indicates an indirect involvement of both gene products in translocation of both metals to sink organs, since they are only weakly expressed in embryos, which is in contrast to AtVIT1 (Zhang et al., 2012). Finally, there are two VIT homologs in wheat, which are located to the tonoplast (Figure 3C), but only one of them, namely TaVIT2, was shown to complement a Mnsensitive yeast strain, pmr1. TaVIT2 was also able to transport $\mathrm{Fe}^{2+}$ and has been employed for biofortification of wheat grains with Fe (Connorton et al., 2017).

Members of the CAX family are metal transporters that mediate efflux of cations into the vacuole (Martinoia et al., 2012).
All plant CAX transporters characterized to date appear to be able to transport $\mathrm{Ca}^{2+}$. Nevertheless, a broad metal substrate range, including $\mathrm{Mn}^{2+}$, is a common characteristic of these proteins. Based on amino acid sequences, the plant CAX family is divided into two clusters, type 1-A and 1-B. Their capability to transport $\mathrm{Mn}^{2+}$ is not related to their phylogenetic association, with AtCAX4, OsCAX1a, and $V v C A X 3$ being members of the type 1-A subfamily and AtCAX2, AtCAX5, OsCAX3, and OsCAX4 being members of the type 1-B subfamily (Martins et al., 2017). AtCAX2 transports a range of cations into the vacuole, including $\mathrm{Mn}^{2+}, \mathrm{Zn}^{2+}$, and $\mathrm{Cd}^{2+}$ (Koren'kov et al., 2007). Knockout analysis suggested that AtCAX2 does not play a major physiological role in $\mathrm{Ca}$ homeostasis, but is more important for vacuolar Mn accumulation (Pittman et al., 2004). However, vacuolar $\mathrm{Mn}^{2+}$ transport was not completely abolished in cax2. AtCAX5 is a likely candidate for this residual activity. AtCAX5 showed a lower $\mathrm{Ca}^{2+}$ and $\mathrm{Mn}^{2+}$ transport activity than AtCAX2 as also a reduced $\mathrm{Ca}^{2+}$ transport capacity (Edmond et al., 2009). Despite the significant sequence similarity and substrate specificity of AtCAX2 and AtCAX5, a clear distinction appeared in their expression pattern and transcriptional regulation. AtCAX5 was expressed in all tissues of Arabidopsis seedlings, particularly in the stem and the root, and at a lower level in the leaf. In addition, there was an increase in AtCAX5 transcripts under conditions of excess $\mathrm{Mn}$, and a reduction in response to excess $\mathrm{Zn}$. In contrast, AtCAX2 was detected at fairly low levels in all tissues, but was not greatly induced by any metal (Edmond et al., 2009). The relevance of these CAX transporters in intracellular $\mathrm{Mn}$ homeostasis is unclear. Since only the Arabidopsis cax 2 mutant showed a growth defect under Mn deficiency (Connorton et al., 2012), future genetic analysis by using cax 2 cax 5 double mutant plants may uncover the physiological function of these transporters in plants.

CAX2-like transporters of other species, as tomato LeCAX2 and barley HvCAX2, transport $\mathrm{Ca}^{2+}$ and $\mathrm{Mn}^{2+}$ into yeast vacuoles upon heterologous expression, but with different transport kinetics (Edmond et al., 2009). HvCAX2 is expressed ubiquitously in roots, shoot, immature spikes, and in seeds, preferentially in the embryo rather than the endosperm. Transcripts of $\mathrm{H} v C A X 2$ increased under excess $\mathrm{Ca}^{2+}$ and $\mathrm{Na}^{+}$. Likewise, LeCAX2 was also expressed in roots and to a higher extend in leaves and fruits (Edmond et al., 2009).

AtCAX4 was expressed at low level in all tissues, and expression increased after $\mathrm{Mn}^{2+}, \mathrm{Na}^{+}$, and $\mathrm{Ni}^{2+}$ treatment (Cheng et al., 2002). Specifically, AtCAX4 transcript levels increased in the root apex and lateral root primordia upon $\mathrm{Mn}^{2+}$ and $\mathrm{Ni}^{2+}$ treatment and decreased if $\mathrm{Ca}^{2+}$ was depleted. Mutation of AtCAX4 led to an arrested growth in seedlings under excess $\mathrm{Cd}^{2+}, \mathrm{Mn}^{2+}$, and auxin (Mei et al., 2009). Previously, a link between auxin-regulated plant development, cytosolic $\mathrm{Ca}^{2+}$, and kinases was described (Robert and Offringa, 2008). Therefore, these findings suggest that the cax4 mutant may have increased cytosolic $\mathrm{Ca}^{2+}$ levels (because of reduced $\mathrm{Ca}^{2+}$ transport into the vacuole), that cause an impaired auxin gradient and altered root development (Mei et al., 2009). Alternatively, the auxin sensitivity phenotype may be a result of altered Mn homeostasis in cax4 mutants, since Mn has an influence 
on auxin responses and auxin metabolism (Mei et al., 2009). VvCAX3 is a ubiquitously expressed vacuolar transporter for both, monovalent and divalent cations in grapevine. Expression of $V v C A X 3$ in yeast restored the growth on media with high $\mathrm{Na}^{+}, \mathrm{Li}^{+}, \mathrm{Cu}^{2+}$, and $\mathrm{Mn}^{2+}$ concentrations (Martins et al., 2017). Interestingly, expression of $V v C A X 3$ decreased during the development in parallel with $\mathrm{Ca}^{2+}$ accumulation in the fruit. It is likely that $\mathrm{VvCAX} 3$ is not only involved in $\mathrm{Ca}^{2+}$ sequestration, but also in the detoxification of trace elements and the mitigation of salt stress, since its transcript level increased under $\mathrm{NaCl}$ treatment (Martins et al., 2017).

Other members of the type 1-B subfamily of CAX transporters are OsCAX3 and OsCAX4 in rice. OsCAX3 is expressed in all plant tissues, and the protein has a capacity to transport $\mathrm{Mn}^{2+}$. Interestingly, when expressed in yeast, next to $\mathrm{Mn}$ tolerance OsCAX3 also conferred $\mathrm{Ca}^{2+}$ tolerance, but to a lower extent compared to other OsCAX transporters. Therefore, OsCAX3, as AtCAX2, might preferentially transport $\mathrm{Mn}^{2+}$, rather than $\mathrm{Ca}^{2+}$, into the vacuole (Kamiya et al., 2005). Nevertheless, future work is needed to confirm its vacuolar localization. By contrast, expression of OsCAX4 provides $\mathrm{Mn}$ and $\mathrm{Cu}$ tolerance to yeast, and OsCAX4 transcripts were increased upon prolonged salt stress in planta (Yamada et al., 2014). A type 1-A transporter of rice, OsCAXla, transports $\mathrm{Ca}^{2+}$ and $\mathrm{Mn}^{2+}$ into yeast vacuoles, but is involved mainly in $\mathrm{Ca}^{2+}$ homeostasis in plant cells under high concentrations of $\mathrm{Ca}^{2+}$ (Kamiya et al., 2006). Further analysis of the function of OsCAX1a in planta showed that the transcript level in roots was increased by $\mathrm{Ca}^{2+}$ and decreased by $\mathrm{Mn}^{2+}, \mathrm{Ni}^{2+}, \mathrm{Mg}^{2+}$, and $\mathrm{Cu}^{2+}$, while shoots showed only an increase of OsCAX1a transcript levels after treatment with $\mathrm{Ca}^{2+}$. The decreased expression of OsCAX1a in response to other divalent cations might be a mechanism to keep high concentrations of cytosolic $\mathrm{Ca}^{2+}$ in order to protect the cell from toxic levels of ions like $\mathrm{Mn}^{2+}$ (Kamiya et al., 2006). Therefore, OsCAX1a may transport $\mathrm{Ca}^{2+}$ into the vacuole under $\mathrm{Ca}^{2+}$ toxicity or regulate $\mathrm{Ca}^{2+}$ homeostasis in the cytosol. In rice, further studies using combined mutants of OsCAX1a, OsCAX3, and $O s C A X 4$ are needed to confirm their relevance in plant $\mathrm{Mn}^{2+}$ and $\mathrm{Ca}^{2+}$ homeostasis.

Members of the CCX family were previously described as transporters of the CAX family. However, because they are phylogenetically closer to the mammalian plasma membrane $\mathrm{K}^{+}$-dependent $\mathrm{Na}^{+} / \mathrm{Ca}^{2+}$ exchangers (NCXs), this gene family, which has five members in Arabidopsis (CCX1-5), was reclassified (Pittman and Hirschi, 2016). Expression of AtCCX3 was induced in roots and flowers upon treatment with $\mathrm{Mn}^{2+}$, and in yeast the expression of AtCCX3 complemented strains defective in $\mathrm{Mn}^{2+}$ export (Morris et al., 2008). Tobacco cells expressing AtCCX3 showed enhanced Mn levels, further suggesting an ability of AtCCX3 to transport $\mathrm{Mn}^{2+}$. The transcript level of $A t C C X 3$ increased in plants upon a treatment with $\mathrm{Na}^{+}, \mathrm{K}^{+}$, and $\mathrm{Mn}^{2+}$, albeit a mutation in AtCCX3 provoked no discernible growth abnormalities under those conditions (Morris et al., 2008).

The genome of Arabidopsis contains six genes encoding NRAMP transporters, whereby AtNRAMP3 and AtNRAMP4 have been localized to the tonoplast (Thomine et al., 2003;
Lanquar et al., 2005). The NRAMP homologs TcNRAMP3 and TcNRAMP4 from Thlaspi caerulescens were also localized to the tonoplast (Oomen et al., 2009). These NRAMP transporters from both species are involved in the transport of $\mathrm{Cd}^{2+}, \mathrm{Fe}^{2+}$, and $\mathrm{Mn}^{2+}$ (Thomine et al., 2000; Oomen et al., 2009; Pottier et al., 2015). In addition, AtNRAMP4 and TcNRAMP4 also transport $\mathrm{Zn}^{2+}$ when expressed in yeast (Lanquar et al., 2004; Oomen et al., 2009; Pottier et al., 2015). AtNRAMP3 and AtNRAMP4 protein levels in leaves were unaffected by Mn deficiency, but expression of AtNRAMP4 was induced under Fe-limited conditions (Lanquar et al., 2010). Both proteins were shown to be responsible for the retrieval of $\mathrm{Fe}$ from vacuoles during seed germination and to mediate the export of vacuolar $\mathrm{Mn}$ in photosynthetic tissues of adult plants (Lanquar et al., 2005, 2010). The nramp3nramp4 double mutant had comparable $\mathrm{Mn}$ concentrations in leaf mesophyll cells as wild type plants, but it showed a strong accumulation of $\mathrm{Mn}$ in the vacuoles (Lanquar et al., 2010). Under Mn deficiency, the double mutant showed a decreased growth which was correlated with reduced photosynthetic activity as a consequence of a shortage of $\mathrm{Mn}$ for the formation of OEC complexes in PSII. In contrast, nramp3nramp4 did not show altered mitochondrial MnSOD activity under Mn deficiency (Lanquar et al., 2010). These results suggest an important role for AtNRAMP3/AtNRAMP4-dependent Mn transit through the vacuole prior to the import into chloroplasts of mesophyll cells.

\section{Manganese Accumulation in Chloroplasts}

Mn plays an extremely important role in chloroplast function, as it is essential for photosynthetic activity. There is a high demand for $\mathrm{Mn}$ in the photosynthetic apparatus, mainly for the formation of the $\mathrm{Mn}_{4} \mathrm{Ca}$-cluster in the OEC of PSII, which is essential for water splitting. In spite of the importance of $\mathrm{Mn}$ for chloroplast function, only recent studies have reported the identification and characterization of $\mathrm{Mn}$ transporters in chloroplast membranes. Two members of the BICAT family, which are related to the GDT1 protein in yeast (Demaegd et al., 2013) and the Mnx protein in the cyanobacterium Synechocystis (Brandenburg et al., 2017), are involved in Mn loading of the chloroplast and the distribution within this organelle (Figure 3A).

The Arabidopsis AtBICAT1 (syn. PAM71, CCHA1) protein is localized in the thylakoid membrane and transports $\mathrm{Ca}^{2+}$ and $\mathrm{Mn}^{2+}$ into the thylakoid lumen (Schneider et al., 2016; Wang et al., 2016; Frank et al., 2019). AtBICAT1 complemented the $\mathrm{Mn}$-sensitive phenotype of the pmrl yeast mutant and mediated $\mathrm{Ca}^{2+}$ influx upon expression in E. coli. bicat1 knockout mutants showed slightly pale green leaves along with compromised growth. Interestingly, growth retardation and photosynthetic activity of bicat 1 could be partially restored by exogenous treatment with $\mathrm{Mn}^{2+}$ (Schneider et al., 2016). In addition, transient elevations of the stromal free $\mathrm{Ca}^{2+}$ concentration, induced by a light-to-dark shift, were increased in bicat 1 mutants (Frank et al., 2019). Based on these findings, AtBICAT1 
presumably functions in $\mathrm{Mn}^{2+}$ and $\mathrm{Ca}^{2+}$ flux into thylakoids for assembly of the $\mathrm{Mn}_{4} \mathrm{Ca}$-cluster, and also in the homeostasis of stromal $\mathrm{Ca}^{2+}$, which regulates numerous processes in chloroplasts (Sello et al., 2018).

AtBICAT2 (syn. PAM71HL, CMT1), the second member of this family, was also described to fulfill functions in chloroplast $\mathrm{Mn}$ and $\mathrm{Ca}^{2+}$ homeostasis (Eisenhut et al., 2018; Frank et al., 2019). In contrast to AtBICAT1, it resides in the chloroplast envelope. Like AtBICAT1, the expression of AtBICAT2 can also alleviate the $\mathrm{Mn}^{2+}$ and $\mathrm{Ca}^{2+}$ sensitivity phenotypes of the pmr1 and pmr1gdt1 yeast mutants, respectively. Disruption of AtBICAT2 resulted in strong chlorosis, severely impaired plant growth, defective thylakoid stacking, and severe reduction of PS II complexes, resulting in diminished photosynthetic activity (Eisenhut et al., 2018; Frank et al., 2019). Consistent with a reduced oxygen evolution capacity, bicat 2 mutant chloroplasts contained less $\mathrm{Mn}$ than those of the wild type (Zhang et al., 2018). Also, mutants were defective in $\mathrm{Ca}^{2+}$ uptake across the chloroplast envelope and showed a strongly dampened dark-induced $\mathrm{Ca}^{2+}$ signal in the stroma (Frank et al., 2019). As consequence, the disruption of AtBICAT2 should also lead to a decreased $\mathrm{Ca}^{2+}$ import into the thylakoid lumen. Taken together, these results indicate that AtBICAT2 functions as an inner envelope transporter responsible for chloroplast $\mathrm{Mn}^{2+}$ and $\mathrm{Ca}^{2+}$ uptake. $\mathrm{Ca}^{2+}$ dynamics and $\mathrm{Mn}$ concentrations in both, stroma and lumen, were likely diminished in bicat 2 mutants, which may explain the stronger phenotype compared to that of bicat1 mutants. The phenotype of bicat1bicat2 double mutants suggest that AtBICAT2 is the limiting step in $\mathrm{Mn}^{2+}$ and $\mathrm{Ca}^{2+}$ delivery to the chloroplast. Further work is needed to unravel the bifunctionality and regulation of BICATs in $\mathrm{Ca}^{2+}$ and $\mathrm{Mn}^{2+}$ homeostasis in chloroplasts.

\section{Manganese Transport Proteins in Endomembranes}

The Arabidopsis CDF protein AtMTP11 was shown to exhibit an important role in $\mathrm{Mn}$ detoxification. The promoter of AtMTP11 had a high activity in root tips, shoot margins, and hydathodes, but not in epidermal cells and trichomes. Expression of AtMTP11 in yeast complemented the $\mathrm{Mn}^{2+}$ hypersensitivity of the pmr1 mutant (Peiter et al., 2007). In Arabidopsis, mtp11 mutants were hypersensitive to elevated $\mathrm{Mn}^{2+}$ levels, whereas AtMTP11-overexpressing lines were hypertolerant (Delhaize et al., 2007; Peiter et al., 2007). As AtMTP11 appeared to be localized to the prevacuolar compartment (PVC) or to the Golgi apparatus (Figure 3A), it was suggested that it functions in the accumulation of excess $\mathrm{Mn}$ either into vacuoles via the PVC or in the secretion to the apoplastic space via vesiclemediated exocytosis (Delhaize et al., 2007; Peiter et al., 2007). The latter pathway was supported by increased Mn concentrations in mtp11 mutants (Peiter et al., 2007). Two poplar homologs of this protein, PtMTP11.1 and PtMTP11.2, were also able to complement the Mn-sensitive yeast mutant $p m r 1$ and targeted to the same Golgi compartments as AtMTP11 (Figure 3C; Peiter et al., 2007). Those genes are therefore likely to function in a similar way. Another MTP11 ortholog in rice, OsMTP11, was also described to be involved in $\mathrm{Mn}$ detoxification. OsMTP11 is induced by high Mn and expressed specifically in conducting tissues (Zhang and Liu, 2017). Interestingly, epigenetic mechanisms (e.g., DNA methylation) were a major factor regulating the expression level of OsMTP11 (Zhang and Liu, 2017). Knockdown of OsMTP11 resulted in growth inhibition in the presence of high concentrations of $\mathrm{Mn}^{2+}$ and also led to increased accumulation of $\mathrm{Mn}$ in shoots and roots. By contrast, the overexpression of OsMTP11 enhanced $\mathrm{Mn}$ tolerance of rice and decreased the accumulation of $\mathrm{Mn}$ in shoots and roots ( $\mathrm{Ma}$ et al., 2018). Stable expression of OsMTP11-GFP in Arabidopsis and transient expression of this construct in rice and tobacco protoplasts showed that OsMTP11 was also located to the Golgi (Figure 3B; Farthing et al., 2017). However, recent studies suggested that OsMTP11 localized to the trans-Golgi network (TGN) when it was expressed in rice protoplasts and tobacco epidermal cells (Ma et al., 2018). Surprisingly, in tobacco epidermal cells, OsMTP11 relocalized to the plasma membrane upon treatment with high extracellular $\mathrm{Mn}^{2+}$ concentrations. These findings suggest that OsMTP11 is required for $\mathrm{Mn}$ homeostasis and contributes to $\mathrm{Mn}^{2+}$ tolerance in rice (Ma et al., 2018).

In the sugar beet relative $B$. vulgaris spp. maritima, the MTP11 homologs BmMTP10 and BmMTP11 were also characterized as $\mathrm{Mn}^{2+}$ transporters by complementation of the pmr1 yeast strain (Erbasol et al., 2013). In barley, transient expression in onion epidermal cells showed that the HvMTP8.1 and HvMTP8.2 proteins, which are most closely related to the vacuolar AtMTP8 (see section Vacuoles as Manganese Stores), were localized to the Golgi apparatus and also complemented the pmrl strain (Pedas et al., 2014). However, the function of those CDF proteins in planta is still unclear.

The Arabidopsis genome encodes 15 P-type $\mathrm{Ca}^{2+}$-ATPases, of which the $\mathrm{P}_{2 A}$-type or ECA (ER-type Calcium ATPase) subfamily has two members involved in endomembrane $\mathrm{Mn}^{2+}$ transport (Kamrul Huda et al., 2013). AtECA1 and AtECA3 both function as a pump for $\mathrm{Ca}^{2+}$ and $\mathrm{Mn}^{2+}$, and localize to the ER and Golgi apparatus, respectively (Figure 3A). Furthermore, AtECA3 was shown to be localized also in subpopulations of endosomes or PVC (Li et al., 2008). AtECA1 and AtECA3 expression in the K616 yeast mutant, defective in the Golgi $\mathrm{Ca}^{2+}$ and $\mathrm{Mn}^{2+}$ pump PMR1 and in the vacuolar $\mathrm{Ca}^{2+}$ pump PMC1, increased its tolerance to toxic levels of $\mathrm{Mn}^{2+}$ and to $\mathrm{Ca}^{2+}$ deficiency (Liang et al., 1997; Wu et al., 2002; Mills et al., 2007). Another ERlocalized ECA transporter in tomato, LCA1, also complemented the growth of K616 yeast under conditions of high $\mathrm{Mn}^{2+}$ and low $\mathrm{Ca}^{2+}$ (Johnson et al., 2009). ecal mutants of Arabidopsis showed impaired growth under $\mathrm{Ca}^{2+}$ deprivation and $\mathrm{Mn}^{2+}$ excess. On high- $\mathrm{Mn}^{2+}$ media, root hair elongation was inhibited in the mutants, suggesting an impairment in tip growth (Wu et al., 2002). Taken together, AtECA1 and LeLCA1 are likely involved in the transport of $\mathrm{Ca}^{2+}$ and $\mathrm{Mn}^{2+}$ from the cytosol into the ER. On the other hand, eca3 was shown to be sensitive to $\mathrm{Mn}$ deficiency and also to $\mathrm{Mn}$ toxicity, but not to $\mathrm{Ca}^{2+}$ deficiency (Mills et al., 2007; Li et al., 2008). Thus, the phenotype of eca3, observed under Mn-deficient conditions, may be due 
to a reduction of the Mn content in the Golgi. Based on these studies, CDF and ECA proteins may be responsible for $\mathrm{Mn}^{2+}$ loading of Golgi-related vesicular compartments, for delivering $\mathrm{Mn}$ to Mn-dependent enzymes and/or for detoxification of Mn via a secretory pathway.

In Arabidopsis, AtNRAMP2 is located in the TGN (Figure 3A) and was shown to be involved in the intracellular allocation of Mn (Alejandro et al., 2017; Gao et al., 2018). AtNRAMP2 is mainly expressed in the vasculature of roots and shoots and was barely induced upon Mn deficiency. Nevertheless, nramp2 mutants showed a hypersensitivity to Mn deficiency and a reduction in Mn contents in vacuoles and chloroplasts with an accompanying reduction in PSII activity under those conditions (Alejandro et al., 2017). Surprisingly, the nramp2nramp3nramp4 triple mutant did not exhibit higher sensitivity to Mn deficiency than the single nramp2 and double nramp3nramp4 mutants (Alejandro et al., 2017). This suggests that the three transporters act in the same pathway to deliver Mn to the chloroplasts.

NRAMP transporters from tomato (LeNRAMP1 and LeNRAMP3) and apple (MbNRAMP1) were also able to transport $\mathrm{Mn}^{2+}$ and located to intracellular vesicles when expressed in yeast cells, but their function in Mn homeostasis is still unclear (Bereczky et al., 2003; Xiao et al., 2008).

ER bodies are fusiform compartments connected to the ER that were found specifically in Brassicales (Matsushima et al., 2003). It has been proposed that ER bodies might play a role in the defense against pathogens and herbivores (Yamada et al., 2011). In Arabidopsis, two VIT transporters, AtMEB1 (Membrane protein of Endoplasmic reticulum Body) and AtMEB2, that localize to the ER body membrane but not to the ER network, have been identified (Yamada et al., 2013). Heterologous expression of AtMEB1 and AtMEB2 in yeast suppressed Fe and Mn toxicity, suggesting that they possibly act as metal transporters. ER bodies are present in hypocotyls of seedlings where they disappear during plant development. In contrast, in roots, ER bodies are constitutively present. Therefore, it has been suggested that MEB transporters may be involved in the sequestration of metals into root ER bodies under metal stress conditions (Yamada et al., 2013).

\section{Manganese Homeostasis in Other Organelles}

In mitochondria, $\mathrm{Mn}$ is crucial for the activity of MnSOD which scavenges ROS generated within the citric acid cycle and the electron transport chain. However, the transport mechanisms for $\mathrm{Mn}^{2+}$ in plant mitochondria still remain to be elucidated. To date, no transporter involved in $\mathrm{Mn}^{2+}$ transport to and from plant mitochondria has been characterized. Nevertheless, in humans, a mitochondrial $\mathrm{Ca}^{2+}$ uniporter (MCU) that is responsible for $\mathrm{Ca}^{2+}$ and $\mathrm{Mn}^{2+}$ loading into the mitochondria has been described (Kirichok et al., 2004). Arabidopsis has six MCU isoforms which are predicted to be localized in mitochondria, except one, cMCU, that is targeted to the chloroplast (Stael et al., 2012). The cMCU protein mediates $\mathrm{Ca}^{2+}$ fluxes across the chloroplast envelope (Teardo et al., 2019).
In humans, MCU is part of a complex named MCUC (MCU complex) which includes other subunits, including the EF hand-containing proteins MICU1 and MICU2 $\left(\mathrm{Ca}^{2+}\right.$-sensing inhibitory subunit). MICU1 plays a decisive role in ion specificity of MCU, allowing it to distinguish between $\mathrm{Ca}^{2+}$ vs. $\mathrm{Mn}^{2+}$ (Kamer et al., 2018). In Arabidopsis, a MICU homolog, AtMICU, that binds $\mathrm{Ca}^{2+}$ and localizes to the mitochondria, was described (Wagner et al., 2015). These findings provoke the idea that a conserved uniporter system, similar to MCUC in humans, may mediate $\mathrm{Ca}^{2+}$ and $\mathrm{Mn}^{2+}$ uptake by plant mitochondria.

In peroxisomes, $\mathrm{Mn}$ is important as a cofactor of the peroxisomal MnSOD. This enzyme is present in some plant species, including pea, cucumber, and pepper (Corpas et al., 2017). However, so far, transporters to load $\mathrm{Mn}$ into the peroxisomes are still missing.

\section{CONCLUSION AND PERSPECTIVES}

The relevance of manganese as a micronutrient of plants is still largely underestimated. For a long time, the accepted dogma among animal and plant biologists has been that the physiological requirement for $\mathrm{Mn}$ by living cells is low and that $\mathrm{Mn}$ uptake exceeds the requirement. However, in natural and in agricultural settings, Mn availability can be a seriously limiting factor for plant growth, which necessitates the operation of high-affinity $\mathrm{Mn}$ transporters in roots and efficient mechanisms of Mn distribution in the plant to cope with Mn shortage. Crops with improved Mn uptake capacity and Mn use efficiency will achieve higher growth and yield under suboptimal Mn availability, primarily by providing sufficient Mn to PSII and thus increasing their photosynthetic efficiency.

There are many unresolved issues in our understanding of $\mathrm{Mn}$ transport and homeostasis, such as the transport of Mn into the xylem - Is it mediated by a vesicle-based secretory mechanism or by plasma membrane-bound exporters? How $\mathrm{Mn}$ is imported by different cell types in the shoot is another open question. Most $\mathrm{Mn}^{2+}$ transporters are not specific, but also able to move other divalent cations, like $\mathrm{Ca}^{2+}, \mathrm{Fe}^{2+}$, $\mathrm{Zn}^{2+}$, or $\mathrm{Cu}^{2+}$, but so far it is still unclear if and how they discriminate between the cations. In humans, the substrate selectivity of a mitochondrial $\mathrm{Mn}$ transporter is altered by interacting $\mathrm{EF}$ hand proteins (Kamer et al., 2018). In this respect, the ability of diverse $\mathrm{Ca}^{2+}$ transport proteins to also permeate $\mathrm{Mn}^{2+}$ (or vice versa) is particular interesting. The possibility that $\mathrm{Ca}^{2+}$ and $\mathrm{Mn}^{2+}$ share transport pathways mediated by ECAs, BICATs, CAXs, and $\mathrm{Ca}^{2+}$ channels, implies an interference of $\mathrm{Mn}^{2+}$ in $\mathrm{Ca}^{2+}$ signaling. In fact, $\mathrm{Mn}^{2+}$ has been demonstrated to act as a signaling agent per se in humans (Wang et al., 2018).

The sensing and signaling of the plant's Mn status is another area yet to be explored: On which level is Mn transport activity regulated by the nutritional status of the plant? This review pointed out some transcriptional changes of $\mathrm{Mn}$ transporter-encoding genes under Mn-toxic and Mn-deficient conditions, but the signaling networks that underlie these changes are still missing. Furthermore, a 
recent systems-wide analysis indicated that $\mathrm{Mn}$ deficiency responses are primarily regulated at the posttranscriptional level (Rodríguez-Celma et al., 2016). Moreover, our understanding of how Mn transport proteins are regulated is very rudimentary. In this respect, a couple of proteins that regulate the subcellular localization of AtNRAMP1 have been identified, revealing links to inositol phosphate and choline homeostasis (Agorio et al., 2017; Gao et al., 2017). As another fascinating case, it has been demonstrated that phosphorylation, ubiquitination, and metal binding modify the stability and localization of AtIRT1, an $\mathrm{Fe}^{2+}$ transporter that contributes to the uptake of $\mathrm{Mn}^{2+}$ (Dubeaux et al., 2018). However, for the vast majority of $\mathrm{Mn}$ transporters, posttranslational modifications and protein-protein interactions are unknown.

Future research has to be focused on all these fundamental aspects. The function, regulation, and co-operation of $\mathrm{Mn}^{2+}$ transport proteins in different plant tissues upon Mn deficiency and excess ought to be understood at transcriptional and at protein level. Such studies will eventually elucidate the mechanisms controlling $\mathrm{Mn}$ acquisition, subcellular compartmentation, and homeostasis in plants, a knowledge

\section{REFERENCES}

Agorio, A., Giraudat, J., Bianchi, M. W., Marion, J., Espagne, C., Castaings, L., et al. (2017). Phosphatidylinositol 3-phosphate-binding protein AtPH1 controls the localization of the metal transporter NRAMP1 in Arabidopsis. Proc. Natl. Acad. Sci. U.S.A. 114, E3354-E3363. doi: 10.1073/pnas.1702975114

Alam, S., Akiha, F., Kamei, S., Huq, S. M. I., and Kawai, S. (2005). Mechanism of potassium alleviation of manganese phytotoxicity in barley. J. Plant Nutr. 28, 889-901. doi: 10.1081/pln-200055572

Alejandro, S., Cailliatte, R., Alcon, C., Dirick, L., Domergue, F., Correia, D., et al. (2017). Intracellular distribution of manganese by the trans-Golgi network transporter NRAMP2 is critical for photosynthesis and cellular redox homeostasis. Plant Cell 29, 3068-3084. doi: 10.1105/tpc.17.00578

Allen, M. D., Kropat, J., Tottey, S., Del Campo, J. A., and Merchant, S. S. (2007). Manganese deficiency in Chlamydomonas results in loss of photosystem II and MnSOD function, sensitivity to peroxides, and secondary phosphorus and iron deficiency. Plant Physiol. 143, 263-277. doi: 10.1104/pp.106.088609

Amao, Y., and Ohashi, A. (2008). Effect of Mn ion on the visible light induced water oxidation activity of photosynthetic organ grana from spinach. Catal. Commun. 10, 217-220. doi: 10.1016/j.catcom.2008.08.022

Andresen, E., Peiter, E., and Küpper, H. (2018). Trace metal metabolism in plants. J. Exp. Bot. 69, 909-954. doi: 10.1093/jxb/erx465

Araki, R., Murata, J., and Murata, Y. (2011). A novel barley yellow stripe 1like transporter (HvYSL2) localized to the root endodermis transports metalphytosiderophore complexes. Plant Cell Physiol. 52, 1931-1940. doi: 10.1093/ pcp/pcr126

Baldisserotto, C., Ferroni, L., Anfuso, E., Pagnoni, A., Fasulo, M. P., and Pancaldi, S. (2007). Responses of Trapa natans L. floating laminae to high concentrations of manganese. Protoplasma 231, 65-82. doi: 10.1007/s00709-007-0242-2

Basu, D., Tian, L., Wang, W., Bobbs, S., Herock, H., Travers, A., et al. (2015). A small multigene hydroxyproline-O-galactosyltransferase family functions in arabinogalactan-protein glycosylation, growth and development in Arabidopsis. BMC Plant Biol. 15:295. doi: 10.1186/s12870-015-0670-7

Bereczky, Z., Wang, H. Y., Schubert, V., Ganal, M., and Bauer, P. (2003). Differential regulation of nramp and irt metal transporter genes in wild type and iron uptake mutants of tomato. J. Biol. Chem. 278, 24697-24704. doi: 10.1074/jbc.m301365200

Blamey, F. P. C., Hernandez-Soriano, M., Cheng, M., Tang, C., Paterson, D., Lombi, E., et al. (2015). Synchrotron-based techniques shed light on mechanisms of plant sensitivity and tolerance to high manganese in the root environment. Plant Physiol. 169, 2006-2020. doi: 10.1104/pp.15.00726 that can be harnessed to develop Mn-efficient germplasm of staple crops.

\section{AUTHOR CONTRIBUTIONS}

$\mathrm{SA}, \mathrm{SH}$, and BM drafted the manuscript. $\mathrm{SA}, \mathrm{SH}, \mathrm{BM}$, and EP finalized the manuscript, approved the final version of the manuscript, and agreed to be accountable for all aspects of the work.

\section{FUNDING}

This work was supported by the European Regional Development Fund (ERDF) within the State Research Focus Program "Molecular Biosciences as a Motor for a KnowledgeBased Economy" (Grant No. ZS/2016/06/79740 to EP). We acknowledge the financial support within the funding program Open Access Publishing by the German Research Foundation (DFG).

Bloom, A. J. (2019). Metal regulation of metabolism. Curr. Opin. Chem. Biol. 49, 33-38. doi: 10.1016/j.cbpa.2018.09.017

Bloom, A. J., and Lancaster, K. M. (2018). Manganese binding to Rubisco could drive a photorespiratory pathway that increases the energy efficiency of photosynthesis. Nat. Plants 4, 414-422. doi: 10.1038/s41477-018-0191-0

Bondarava, N., Un, S., and Krieger-Liszkay, A. (2007). Manganese binding to the 23 $\mathrm{kDa}$ extrinsic protein of photosystem II. Biochim. Biophys. Acta Bioenerg. 1767, 583-588. doi: 10.1016/j.bbabio.2007.01.001

Bowler, C., Van Camp, W., Van Montagu, M., Inzé, D., and Asada, K. (1994). Superoxide dismutase in plants. Crit. Rev. Plant Sci. 13, 199-218.

Brandenburg, F., Schoffman, H., Kurz, S., Krämer, U., Keren, N., Weber, A. P. M., et al. (2017). The Synechocystis manganese exporter Mnx is essential for manganese homeostasis in cyanobacteria. Plant Physiol. 173, 1798-1810. doi: 10.1104/pp.16.01895

Bricker, T. M., Roose, J. L., Fagerlund, R. D., Frankel, L. K., and Eaton-Rye, J. J. (2012). The extrinsic proteins of Photosystem II. Biochim. Biophys. Acta Bioenerg. 1817, 121-142.

Broadley, M., Brown, P., Cakmak, I., Rengel, Z., and Zhao, F. (2012). "Function of nutrients: micronutrients," in Marschner's Mineral Nutrition of Higher Plants, 3rd Edn, ed. P. Marschner (Oxford: Elsevier), 191-249.

Burnell, J. N. (1988). "The biochemistry of manganese in plants," in Manganese in Soils and Plants, eds R. D. Graham, R. J. Hannam, and N. C. Uren (Dordrecht: Springer), 125-137.

Cailliatte, R., Schikora, A., Briat, J.-F., Mari, S., and Curie, C. (2010). Highaffinity manganese uptake by the metal transporter NRAMP1 is essential for Arabidopsis growth in low manganese conditions. Plant Cell 22, 904-917. doi: 10.1105/tpc.109.073023

Cao, F. Q., Werner, A. K., Dahncke, K., Romeis, T., Liu, L. H., and Witte, C. P. (2010). Identification and characterization of proteins involved in rice urea and arginine catabolism. Plant Physiol. 154, 98-108. doi: 10.1104/pp.110.160929

Cao, J. (2019). Molecular evolution of the vacuolar iron transporter (VIT) family genes in 14 plant species. Genes 10:144. doi: 10.3390/genes10020144

Castaings, L., Caquot, A., Loubet, S., and Curie, C. (2016). The high-affinity metal transporters NRAMP1 and IRT1 team up to take up iron under sufficient metal provision. Sci. Rep. 6, 37222-37222. doi: 10.1038/srep37222

Chen, Z., Fujii, Y., Yamaji, N., Masuda, S., Takemoto, Y., Kamiya, T., et al. (2013). $\mathrm{Mn}$ tolerance in rice is mediated by MTP8.1, a member of the cation diffusion facilitator family. J. Exp. Bot. 64, 4375-4387. doi: 10.1093/jxb/ert243

Cheng, N.-H., Pittman, J. K., Shigaki, T., and Hirschi, K. D. (2002). Characterization of CAX4, an Arabidopsis $\mathrm{H}^{+} /$cation antiporter. Plant Physiol. 128, 1245-1254. doi: 10.1104/pp.010857 
Chereskin, B. M., and Castelfranco, P. A. (1982). Effects of iron and oxygen on chlorophyll biosynthesis. Plant Physiol. 69, 112-116. doi: 10.1104/pp.69.1.112

Chu, H.-H., Car, S., Socha, A. L., Hindt, M. N., Punshon, T., and Guerinot, M. L. (2017). The Arabidopsis MTP8 transporter determines the localization of manganese and iron in seeds. Sci. Rep. 7, 11024-11024. doi: 10.1038/s41598017-11250-9

Clairmont, K. B., Hagar, W. G., and Davis, E. A. (1986). Manganese toxicity to chlorophyll synthesis in tobacco callus. Plant Physiol. 80, 291-293. doi: 10.1104/ pp.80.1.291

Collin, S., Justin, A. M., Cantrel, C., Arondel, V., and Kader, J. C. (1999). Identification of AtPIS, a phosphatidylinositol synthase from Arabidopsis. Eur. J. Biochem. 262, 652-658. doi: 10.1046/j.1432-1327.1999.00378.x

Connorton, J. M., Jones, E. R., Rodríguez-Ramiro, I., Fairweather-Tait, S., Uauy, C., and Balk, J. (2017). Wheat vacuolar iron transporter TaVIT2 transports Fe and Mn and is effective for biofortification. Plant Physiol. 174, 2434-2444. doi: 10.1104/pp.17.00672

Connorton, J. M., Webster, R. E., Cheng, N., and Pittman, J. K. (2012). Knockout of multiple Arabidopsis cation $/ \mathrm{H}^{+}$exchangers suggests isoform-specific roles in metal stress response, germination and seed mineral nutrition. PLoS One 7:e47455. doi: 10.1371/journal.pone.0047455

Cornah, J. E., Roper, J. M., Singh, D. P., and Smith, A. G. (2002). Measurement of ferrochelatase activity using a novel assay suggests that plastids are the major site of haem biosynthesis in both photosynthetic and non-photosynthetic cells of pea (Pisum sativum L.). Biochem. J. 362, 423-432. doi: 10.1042/bj3620423

Corpas, F. J., Barroso, J. B., Palma, J. M., and Rodriguez-Ruiz, M. (2017). Plant peroxisomes: a nitro-oxidative cocktail. Redox Biol. 11, 535-542. doi: 10.1016/j. redox.2016.12.033

Curie, C., Alonso, J. M., Le Jean, M., Ecker, J. R., and Briat, J.-F. (2000). Involvement of NRAMP1 from Arabidopsis thaliana in iron transport. Biochem. J. 347:749. doi: 10.1042/0264-6021:3470749

Delhaize, E., Gruber, B. D., Pittman, J. K., White, R. G., Leung, H., Miao, Y., et al. (2007). A role for the AtMTP11 gene of Arabidopsis in manganese transport and tolerance. Plant J. 51, 198-210. doi: 10.1111/j.1365-313x.2007.03138.x

Delhaize, E., Kataoka, T., Hebb, D. M., White, R. G., and Ryan, P. R. (2003). Genes encoding proteins of the cation diffusion facilitator family that confer manganese tolerance. Plant Cell 15, 1131-1142. doi: 10.1105/tpc.009134

Demaegd, D., Colinet, A. S., Deschamps, A., and Morsomme, P. (2014). Molecular evolution of a novel family of putative calcium transporters. PLoS One 9:e100851. doi: 10.1371/journal.pone.0100851

Demaegd, D., Foulquier, F., Colinet, A. S., Gremillon, L., Legrand, D., Mariot, P., et al. (2013). Newly characterized Golgi-localized family of proteins is involved in calcium and $\mathrm{pH}$ homeostasis in yeast and human cells. Proc. Natl. Acad. Sci. U.S.A. 110, 6859-6864. doi: 10.1073/pnas.1219871110

Doncheva, S., Poschenrieder, C., Stoyanova, Z., Georgieva, K., Velichkova, M., and Barceló, J. (2009). Silicon amelioration of manganese toxicity in $\mathrm{Mn}$-sensitive and Mn-tolerant maize varieties. Environ. Exp. Bot. 65, 189-197. doi: 10.1016/ j.envexpbot.2008.11.006

Dou, C. M., Fu, X. P., Chen, X. C., Shi, J. Y., and Chen, Y. X. (2009). Accumulation and detoxification of manganese in hyperaccumulator Phytolacca americana. Plant Biol. 11, 664-670. doi: 10.1111/j.1438-8677.2008.00163.x

Dubeaux, G., Neveu, J., Zelazny, E., and Vert, G. (2018). Metal sensing by the IRT1 transporter-receptor orchestrates its own degradation and plant metal nutrition. Mol. Cell 69, 953-964. doi: 10.1016/j.molcel.2018.02.009

Dučić, T., and Polle, A. (2007). Manganese toxicity in two varieties of Douglas fir (Pseudotsuga menziesii var. viridis and glauca) seedlings as affected by phosphorus supply. Funct. Plant Biol. 34, 31-40.

Eckhardt, U., Mas Marques, A., and Buckhout, T. J. (2001). Two iron-regulated cation transporters from tomato complement metal uptake-deficient yeast mutants. Plant Mol. Biol. 45, 437-448.

Edmond, C., Shigaki, T., Ewert, S., Nelson, M. D., Connorton, J. M., Chalova, V., et al. (2009). Comparative analysis of CAX2-like cation transporters indicates functional and regulatory diversity. Biochem. J. 418, 145-154. doi: 10.1042/ BJ20081814

Egelund, J., Petersen, B. L., Motawia, M. S., Damager, I., Faik, A., Olsen, C. E., et al. (2006). Arabidopsis thaliana RGXT1 and RGXT2 encode Golgilocalized $(1,3)$-alpha-D-xylosyltransferases involved in the synthesis of pectic rhamnogalacturonan-II. Plant Cell 18, 2593-2607. doi: 10.1105/tpc.105.036566
Eisenhut, M., Hoecker, N., Schmidt, S. B., Basgaran, R. M., Flachbart, S., Jahns, P., et al. (2018). The plastid envelope CHLOROPLAST MANGANESE TRANSPORTER1 is essential for manganese homeostasis in Arabidopsis. Mol. Plant 11, 955-969. doi: 10.1016/j.molp.2018.04.008

Emsley, J. (2003). Nature's Building Blocks: An A-Z Guide to the Elements. Oxford: Oxford University Press.

Engelsma, G. (1972). A possible role of divalent manganese ions in the photoinduction of phenylalanine ammonia-lyase. Plant Physiol. 50, 599-602. doi: 10.1104/pp.50.5.599

Erbasol, I., Bozdag, G. O., Koc, A., Pedas, P., and Karakaya, H. C. (2013). Characterization of two genes encoding metal tolerance proteins from Beta vulgaris subspecies maritima that confers manganese tolerance in yeast. Biometals 26, 795-804. doi: 10.1007/s10534-013-9658-7

Eroglu, S., Giehl, R. F. H., Meier, B., Takahashi, M., Terada, Y., Ignatyev, K., et al. (2017). Metal tolerance protein 8 mediates manganese homeostasis and iron reallocation during seed development and germination. Plant Physiol. 174, 1633-1647. doi: 10.1104/pp.16.01646

Eroglu, S., Meier, B., von Wirén, N., and Peiter, E. (2016). The vacuolar manganese transporter MTP8 determines tolerance to iron deficiency-induced chlorosis in Arabidopsis. Plant Physiol. 170, 1030-1045. doi: 10.1104/pp.15.01194

Farthing, E. C., Menguer, P. K., Fett, J. P., and Williams, L. E. (2017). OsMTP11 is localised at the Golgi and contributes to Mn tolerance. Sci. Rep. 7:15258. doi: 10.1038/s41598-017-15324-6

Farzadfar, S., Zarinkamar, F., and Hojati, M. (2017). Magnesium and manganese affect photosynthesis, essential oil composition and phenolic compounds of Tanacetum parthenium. Plant Physiol. Biochem. 112, 207-217. doi: 10.1016/j. plaphy.2017.01.002

Fecht-Christoffers, M. M., Führs, H., Braun, H. P., and Horst, W. J. (2006). The role of hydrogen peroxide-producing and hydrogen peroxide-consuming peroxidases in the leaf apoplast of cowpea in manganese tolerance. Plant Physiol. 140, 1451-1463. doi: 10.1104/pp.105.070474

Fernando, D. R., Bakkaus, E. J., Perrier, N., Baker, A. J., Woodrow, I. E., Batianoff, G. N., et al. (2006a). Manganese accumulation in the leaf mesophyll of four tree species: a PIXE/EDAX localization study. New Phytol. 171, 751-758. doi: 10.1111/j.1469-8137.2006.01783.x

Fernando, D. R., Batianoff, G. N., Baker, A. J., and Woodrow, I. E. (2006b). In vivo localization of manganese in the hyperaccumulator Gossia bidwillii (Benth.) N. Snow \& Guymer (Myrtaceae) by cryo-SEM/EDAX. Plant Cell Environ. 29, 1012-1020. doi: 10.1111/j.1365-3040.2006.01498.x

Fernando, D. R., and Lynch, J. P. (2015). Manganese phytotoxicity: new light on an old problem. Annals Bot. 116, 313-319. doi: 10.1093/aob/mcv111

Fernando, D. R., Mizuno, T., and Woodrow, I. E. (2010). Characterization of foliar manganese (Mn) in Mn (hyper) accumulators using X-ray absorption spectroscopy. New Phytol. 188, 1014-1027. doi: 10.1111/j.1469-8137.2010. 03431.x

Ferrandon, M., and Chamel, A. R. (1988). Cuticular retention, foliar absorption and translocation of $\mathrm{Fe}, \mathrm{Mn}$ and $\mathrm{Zn}$ supplied in organic and inorganic form. J. Plant Nutr. 11, 247-263. doi: 10.1080/01904168809363800

Frank, J., Happeck, R., Meier, B., Hoang, M. T. T., Stribny, J., Hause, G., et al. (2019). Chloroplast-localized BICAT proteins shape stromal calcium signals and are required for efficient photosynthesis. New Phytol. 221, 866-880. doi: 10.1111/nph.15407

Fu, X.-Z., Zhou, X., Xing, F., Ling, L.-L., Chun, C.-P., Cao, L., et al. (2017). Genome-wide identification, cloning and functional analysis of the Zinc/IronRegulated Transporter-Like Protein (ZIP) gene family in trifoliate orange (Poncirus trifoliata L. Raf.). Front. Plant Sci. 8:588. doi: 10.3389/fpls.2017.00588

Führs, H., Behrens, C., Gallien, S., Heintz, D., Van Dorsselaer, A., Braun, H. P., et al. (2010). Physiological and proteomic characterization of manganese sensitivity and tolerance in rice (Oryza sativa) in comparison with barley (Hordeum vulgare). Ann. Bot. 105, 1129-1140. doi: 10.1093/aob/mcq046

Gao, H., Xie, W., Yang, C., Xu, J., Li, J., Wang, H., et al. (2018). NRAMP2, a transGolgi network-localized manganese transporter, is required for Arabidopsis root growth under manganese deficiency. New Phytol. 217, 179-193. doi: 10.1111/ nph. 14783

Gao, Y. Q., Chen, J. G., Chen, Z. R., An, D., Lv, Q. Y., Han, M. L., et al. (2017). A new vesicle trafficking regulator CTL1 plays a crucial role in ion homeostasis. PLoS Biol. 15:e2002978. doi: 10.1371/journal.pbio.2002978 
George, T. S., French, A. S., Brown, L. K., Karley, A. J., White, P. J., Ramsay, L., et al. (2014). Genotypic variation in the ability of landraces and commercial cereal varieties to avoid manganese deficiency in soils with limited manganese availability: is there a role for root-exuded phytases? Physiol. Plant. 151, 243256. doi: $10.1111 /$ ppl.12151

Gherardi, M. J., and Rengel, Z. (2004). The effect of manganese supply on exudation of carboxylates by roots of lucerne (Medicago sativa). Plant Soil 260, 271-282. doi: 10.1023/b:plso.0000030182.11473.3b

Giles, C. D., Brown, L. K., Adu, M. O., Mezeli, M. M., Sandral, G. A., Simpson, R. J., et al. (2017). Response-based selection of barley cultivars and legume species for complementarity: root morphology and exudation in relation to nutrient source. Plant Sci. 255, 12-28. doi: 10.1016/j.plantsci.2016.11.002

Glynn, S. E., Baker, P. J., Sedelnikova, S. E., Davies, C. L., Eadsforth, T. C., Levy, C. W., et al. (2005). Structure and mechanism of imidazoleglycerol-phosphate dehydratase. Structure 13, 1809-1817. doi: 10.1016/j.str.2005.08.012

Goulding, K. W. T. (2016). Soil acidification and the importance of liming agricultural soils with particular reference to the United Kingdom. Soil Use Manag. 32, 390-399. doi: 10.1111/sum.12270

Gregory, A. L., Hurley, B. A., Tran, H. T., Valentine, A. J., She, Y. M., Knowles, V. L., et al. (2009). In vivo regulatory phosphorylation of the phosphoenolpyruvate carboxylase AtPPC1 in phosphate-starved Arabidopsis thaliana. Biochem. J. 420, 57-65. doi: 10.1042/BJ20082397

Guerinot, M. L. (2000). The ZIP family of metal transporters. Biochim. Biophys. Acta Biomembr. 1465, 190-198. doi: 10.1016/s0005-2736(00)00 138-3

Hajiboland, R. (2012). "Effect of micronutrient deficiencies on plants stress responses," in Abiotic Stress Responses in Plants, eds P. Ahmad and M. Prasad (New York, NY: Springer), 283-329. doi: 10.1007/978-1-4614-0634-1\_16

Hansel, C. M., Zeiner, C. A., Santelli, C. M., and Webb, S. M. (2012). Mn(II) oxidation by an ascomycete fungus is linked to superoxide production during asexual reproduction. Proc. Natl. Acad. Sci. U.S.A. 109, 12621-12625. doi: 10. 1073/pnas. 1203885109

Hashimoto, K., Eckert, C., Anschütz, U., Scholz, M., Held, K., Waadt, R., et al. (2012). Phosphorylation of calcineurin B-like (CBL) calcium sensor proteins by their CBL-interacting protein kinases (CIPKs) is required for full activity of CBL-CIPK complexes toward their target proteins. J. Biol. Chem. 287, 7956-7968. doi: 10.1074/jbc.M111.279331

Hauck, M., Paul, A., Gross, S., and Raubuch, M. (2003). Manganese toxicity in epiphytic lichens: chlorophyll degradation and interaction with iron and phosphorus. Environ. Exp. Bot. 49, 181-191. doi: 10.1016/s0098-8472(02) 00069-2

Hebbern, C. A., Laursen, K. H., Ladegaard, A. H., Schmidt, S. B., Pedas, P., Bruhn, D., et al. (2009). Latent manganese deficiency increases transpiration in barley (Hordeum vulgare). Physiol. Plant. 135, 307-316. doi: 10.1111/j.13993054.2008.01188.x

Hebbern, C. A., Pedas, P., Schjoerring, J. K., Knudsen, L., and Husted, S. (2005). Genotypic differences in manganese efficiency: field experiments with winter barley (Hordeum vulgare L.). Plant Soil 272, 233-244. doi: 10.1007/s11104-0045048-9

Heckman, J. R., Clarke, B. B., and Murphy, J. A. (2003). Optimizing manganese fertilization for the suppression of take-all patch disease on creeping bentgrass. Crop Sci. 43, 1395-1398. doi: 10.2135/cropsci2003.1395

Heine, G., Max, J. F. J., Führs, H., Moran-Puente, D. W., Heintz, D., and Horst, W. J. (2011). Effect of manganese on the resistance of tomato to Pseudocercospora fuligena. J. Plant Nutr. Soil Sci. 174, 827-836. doi: 10.1002/ jpln.201000440

Henriques, F. S. (2004). Reduction in chloroplast number accounts for the decrease in the photosynthetic capacity of Mn-deficient pecan leaves. Plant Sci. 166, 1051-1055. doi: 10.1016/j.plantsci.2003.12.022

Hirschi, K. D., Korenkov, V. D., Wilganowski, N. L., and Wagner, G. J. (2000). Expression of Arabidopsis CAX2 in tobacco. Altered metal accumulation and increased manganese tolerance. Plant Physiol. 124, 125-134. doi: 10.1104/pp. 124.1.125

Hoecker, N., Leister, D., and Schneider, A. (2017). Plants contain small families of UPF0016 proteins including the PHOTOSYNTHESIS AFFECTED MUTANT71 transporter. Plant Signal. Behav 12:e1278101. doi: 10.1080/ 15592324.2016.1278101
Hou, L., Gu, D., Li, Y., Li, J., Li, J., Chen, X., et al. (2019). Phylogenetic and expression analysis of Mn-CDF transporters in pear (Pyrus bretschneideri Rehd.). Plant Mol. Biol. Report. 37, 98-110. doi: 10.1007/s11105-019-01142-9

Hsieh, M. H., Chang, C. Y., Hsu, S. J., and Chen, J. J. (2008). Chloroplast localization of methylerythritol 4-phosphate pathway enzymes and regulation of mitochondrial genes in ispD and ispE albino mutants in Arabidopsis. Plant Mol. Biol. 66, 663-673. doi: 10.1007/s11103-008-9297-5

Huang, Y. L., Yang, S., Long, G. X., Zhao, Z. K., Li, X. F., and Gu, M. H. (2016). Manganese toxicity in sugarcane plantlets grown on acidic soils of southern China. PLoS One 11:e0148956. doi: 10.1371/journal.pone.0148956

Husted, S., Laursen, K. H., Hebbern, C. A., Schmidt, S. B., Pedas, P., Haldrup, A., et al. (2009). Manganese deficiency leads to genotype-specific changes in fluorescence induction kinetics and state transitions. Plant Physiol. 150, 825-833. doi: 10.1104/pp.108.134601

Ihnatowicz, A., Siwinska, J., Meharg, A. A., Carey, M., Koornneef, M., and Reymond, M. (2014). Conserved histidine of metal transporter AtNRAMP1 is crucial for optimal plant growth under manganese deficiency at chilling temperatures. New Phytol. 202, 1173-1183. doi: 10.1111/nph.12737

Ishimaru, Y., Masuda, H., Bashir, K., Inoue, H., Tsukamoto, T., Takahashi, M., et al. (2010). Rice metal-nicotianamine transporter, OsYSL2, is required for the long-distance transport of iron and manganese. Plant J. 62, 379-390. doi: 10.1111/j.1365-313X.2010.04158.x

Ishimaru, Y., Takahashi, R., Bashir, K., Shimo, H., Senoura, T., Sugimoto, K., et al. (2012). Characterizing the role of rice NRAMP5 in manganese, iron and cadmium transport. Sci. Rep. 2:286. doi: 10.1038/srep00286

Jauregui, M. A., and Reisenauer, H. M. (1982). Dissolution of oxides of manganese and iron by root exudate components. Soil Sci. Soc. Am. J. 46, 314-317. doi: 10.2136/sssaj1982.03615995004600020020x

Johnson, N. A., Liu, F., Weeks, P. D., Hentzen, A. E., Kruse, H. P., Parker, J. J., et al. (2009). A tomato ER-type $\mathrm{Ca}^{2+}$-ATPase, LCA1, has a low thapsigarginsensitivity and can transport manganese. Arch. Biochem. Biophys. 481, 157-168. doi: 10.1016/j.abb.2008.11.010

Kamer, K. J., Sancak, Y., Fomina, Y., Meisel, J. D., Chaudhuri, D., Grabarek, Z., et al. (2018). MICU1 imparts the mitochondrial uniporter with the ability to discriminate between $\mathrm{Ca}^{2+}$ and $\mathrm{Mn}^{2+}$. Proc. Natl. Acad. Sci. U.S.A. 115, E7960-E7969. doi: 10.1073/pnas.1807811115

Kamiya, T., Akahori, T., Ashikari, M., and Maeshima, M. (2006). Expression of the vacuolar $\mathrm{Ca}^{2+} / \mathrm{H}^{+}$exchanger, OsCAX1a, in rice: cell and age specificity of expression, and enhancement by $\mathrm{Ca}^{2+}$. Plant Cell Physiol. 47, 96-106. doi: $10.1093 / \mathrm{pcp} / \mathrm{pci} 227$

Kamiya, T., Akahori, T., and Maeshima, M. (2005). Expression profile of the genes for rice cation $/ \mathrm{H}^{+}$exchanger family and functional analysis in yeast. Plant Cell Physiol. 46, 1735-1740. doi: 10.1093/pcp/pci173

Kamrul Huda, K. M., Yadav, S., Akhter Banu, M. S., Trivedi, D. K., and Tuteja, N. (2013). Genome-wide analysis of plant-type II $\mathrm{Ca}^{2+}$ ATPases gene family from rice and Arabidopsis: potential role in abiotic stresses. Plant Physiol. Biochem. 65, 32-47. doi: 10.1016/j.plaphy.2013.01.002

Khabaz-Saberi, H., Setter, T. L., and Waters, I. (2006). Waterlogging induces high to toxic concentrations of iron, aluminum, and manganese in wheat varieties on acidic soil. J. Plant Nutr. 29, 899-911. doi: 10.1080/01904160600649161

Kim, K. N., Lee, J. S., Han, H., Choi, S. A., Go, S. J., and Yoon, I. S. (2003). Isolation and characterization of a novel rice $\mathrm{Ca}^{2+}$-regulated protein kinase gene involved in responses to diverse signals including cold, light, cytokinins, sugars and salts. Plant Mol. Biol. 52, 1191-1202. doi: 10.1023/b:plan.0000004330. 62660.a2

Kim, S. A., Punshon, T., Lanzirotti, A., Li, L., Alonso, J. M., Ecker, J. R., et al. (2006). Localization of iron in Arabidopsis seed requires the vacuolar membrane transporter VIT1. Science 314, 1295-1298. doi: 10.1126/science.1132563

Kirichok, Y., Krapivinsky, G., and Clapham, D. E. (2004). The mitochondrial calcium uniporter is a highly selective ion channel. Nature 427, 360-364. doi: 10.1038 /nature02246

Koike, S., Inoue, H., Mizuno, D., Takahashi, M., Nakanishi, H., Mori, S., et al. (2004). OsYSL2 is a rice metal-nicotianamine transporter that is regulated by iron and expressed in the phloem. Plant J. 39, 415-424. doi: 10.1111/j.1365313x.2004.02146.x

Köllner, T. G., Held, M., Lenk, C., Hiltpold, I., Turlings, T. C. J., Gershenzon, J., et al. (2008). A maize (E)- $\beta$-caryophyllene synthase implicated in indirect 
defense responses against herbivores is not expressed in most American maize varieties. Plant Cell 20, 482-494. doi: 10.1105/tpc.107.051672

Koren'kov, V., Park, S., Cheng, N. H., Sreevidya, C., Lachmansingh, J., Morris, J., et al. (2007). Enhanced $\mathrm{Cd}^{2+}$-selective root-tonoplast-transport in tobaccos expressing Arabidopsis cation exchangers. Planta 225, 403-411. doi: 10.1007/ s00425-006-0352-7

Korshunova, Y. O., Eide, D., Clark, W. G., Guerinot, M. L., and Pakrasi, H. B. (1999). The IRT1 protein from Arabidopsis thaliana is a metal transporter with a broad substrate range. Plant Mol. Biol. 40, 37-44.

Lambers, H., Hayes, P. E., Laliberté, E., Oliveira, R. S., and Turner, B. L. (2015). Leaf manganese accumulation and phosphorus-acquisition efficiency. Trends Plant Sci. 20, 83-90. doi: 10.1016/j.tplants.2014.10.007

Lane, B. G. (2002). Oxalate, germins, and higher-plant pathogens. IUBMB Life 53, 67-75. doi: 10.1080/15216540211474

Lanquar, V., Lelièvre, F., Barbier-Brygoo, H., and Thomine, S. (2004). Regulation and function of AtNRAMP4 metal transporter protein. Soil Sci. Plant Nutr. 50, 1141-1150. doi: 10.1080/00380768.2004.10408587

Lanquar, V., Lelièvre, F., Bolte, S., Hamès, C., Alcon, C., Neumann, D., et al. (2005). Mobilization of vacuolar iron by AtNRAMP3 and AtNRAMP4 is essential for seed germination on low iron. EMBO J. 24, 4041-4051. doi: 10.1038/sj.emboj. 7600864

Lanquar, V., Schnell Ramos, M., Lelièvre, F., Barbier-Brygoo, H., Krieger-Liszkay, A., Krämer, U., et al. (2010). Export of vacuolar manganese by AtNRAMP3 and AtNRAMP4 is required for optimal photosynthesis and growth under manganese deficiency. Plant Physiol. 152, 1986-1999. doi: 10.1104/pp.109. 150946

LeClere, S., Tellez, R., Rampey, R. A., Matsuda, S. P. T., and Bartel, B. (2002). Characterization of a family of IAA-amino acid conjugate hydrolases from Arabidopsis. J. Biol. Chem. 277, 20446-20452. doi: 10.1074/jbc.m11195 5200

Lešková, A., Giehl, R. F. H., Hartmann, A., Fargašová, A., and von Wirén, N. (2017). Heavy metals induce iron deficiency responses at different hierarchic and regulatory levels. Plant Physiol. 174, 1648-1668. doi: 10.1104/pp.16.01916

Li, C., Wang, P., Menzies, N. W., Lombi, E., and Kopittke, P. M. (2017). Effects of changes in leaf properties mediated by methyl jasmonate (MeJA) on foliar absorption of Zn, Mn and Fe. Ann. Bot. 120, 405-415. doi: 10.1093/aob/mcx063

Li, J. Y., Liu, J., Dong, D., Jia, X., Mccouch, S. R., and Kochian, L. V. (2014). Natural variation underlies alterations in Nramp aluminum transporter (NRAT1) expression and function that play a key role in rice aluminum tolerance. Proc. Natl. Acad. Sci. U.S.A. 111, 6503-6508. doi: 10.1073/pnas.1318975111

Li, L., Xu, X., Chen, C., and Shen, Z. (2016). Genome-wide characterization and expression analysis of the Germin-like protein family in rice and Arabidopsis. Int. J. Mol. Sci. 17:1622. doi: 10.3390/ijms17101622

Li, L., and Yang, X. (2018). The essential element manganese, oxidative stress, and metabolic diseases: links and interactions. Oxid. Med. Cell. Longev. 2018:7580707. doi: 10.1155/2018/7580707

Li, Q., Chen, L. S., Jiang, H. X., Tang, N., Yang, L. T., Lin, Z. H., et al. (2010). Effects of manganese-excess on $\mathrm{CO}_{2}$ assimilation, ribulose-1,5-bisphosphate carboxylase/oxygenase, carbohydrates and photosynthetic electron transport of leaves, and antioxidant systems of leaves and roots in Citrus grandis seedlings. BMC Plant Biol. 10:42. doi: 10.1186/1471-2229-10-42

Li, X., Chanroj, S., Wu, Z., Romanowsky, S. M., Harper, J. F., and Sze, H. (2008). A distinct endosomal $\mathrm{Ca}^{2+} / \mathrm{Mn}^{2+}$ pump affects root growth through the secretory process. Plant Physiol. 147, 1675-1689. doi: 10.1104/pp.108.11 9909

Liang, F., Cunningham, K. W., Harper, J. F., and Sze, H. (1997). ECA1 complements yeast mutants defective in $\mathrm{Ca}^{2+}$ pumps and encodes an endoplasmic reticulumtype $\mathrm{Ca}^{2+}$-ATPase in Arabidopsis thaliana. Proc. Natl. Acad. Sci. U.S.A. 94, 8579-8584. doi: 10.1073/pnas.94.16.8579

Lidon, F. C., Barreiro, M. G., and Ramalho, J. C. (2004). Manganese accumulation in rice: implications for photosynthetic functioning. J. Plant Physiol. 161, 1235-1244. doi: 10.1016/j.jplph.2004.02.003

Liu, J., Gao, Y., Tang, Y., Wang, D., Chen, X., Yao, Y., et al. (2019). Genome-wide identification, comprehensive gene feature, evolution, and expression analysis of plant metal tolerance proteins in tobacco under heavy metal toxicity. Front. Genet. 10:345. doi: 10.3389/fgene.2019.00345

Long, L., Persson, D. P., Duan, F., Jørgensen, K., Yuan, L., Schjoerring, J. K., et al. (2018). The iron-regulated transporter 1 plays an essential role in uptake, translocation and grain-loading of manganese, but not iron, in barley. New Phytol. 217, 1640-1653. doi: 10.1111/nph.14930

Longnecker, N. E., Graham, R. D., and Card, G. (1991). Effects of manganese deficiency on the pattern of tillering and development of barley (Hordeum vulgare c.v. galleon). Field Crops Res. 28, 85-102. doi: 10.1016/0378-4290(91) 90076-8

López-Millán, A. F., Ellis, D. R., and Grusak, M. A. (2004). Identification and characterization of several new members of the ZIP family of metal ion transporters in Medicago truncatula. Plant Mol. Biol. 54, 583-596. doi: 10.1023/ b:plan.0000038271.96019.aa

Lovely, D. R. (1995). Microbial reduction of iron, manganese, and other metals. Adv. Agron. 54, 175-231. doi: 10.1016/s0065-2113(08)60900-1

Ma, G., Li, J., Li, J., Li, Y., Gu, D., Chen, C., et al. (2018). OsMTP11, a trans-Golgi network localized transporter, is involved in manganese tolerance in rice. Plant Sci. 274, 59-69. doi: 10.1016/j.plantsci.2018.05.011

Martinoia, E., Meyer, S., De Angeli, A., and Nagy, R. (2012). Vacuolar transporters in their physiological context. Annu. Rev. Plant Biol. 63, 183-213. doi: 10.1146/ annurev-arplant-042811-105608

Martins, V., Carneiro, F., Conde, C., Sottomayor, M., and Gerós, H. (2017). The grapevine VvCAX3 is a cation $/ \mathrm{H}^{+}$exchanger involved in vacuolar $\mathrm{Ca}^{2+}$ homeostasis. Planta 246, 1083-1096. doi: 10.1007/s00425-017-2754-0

Matsushima, R., Hayashi, Y., Yamada, K., Shimada, T., Nishimura, M., and HaraNishimura, I. (2003). The ER body, a novel endoplasmic reticulum-derived structure in Arabidopsis. Plant Cell Physiol. 44, 661-666. doi: 10.1093/pcp/ pcg089

McNaughton, R. L., Reddi, A. R., Clement, M. H. S., Sharma, A., Barnese, K., Rosenfeld, L., et al. (2010). Probing in vivo $\mathrm{Mn}^{2+}$ speciation and oxidative stress resistance in yeast cells with electron-nuclear double resonance spectroscopy. Proc. Natl. Acad. Sci U.S.A. 107, 15335-15339. doi: 10.1073/pnas.1009648107

McNear, D. H., and Küpper, J. V. (2014). Mechanisms of trichome-specific Mn accumulation and toxicity in the Ni hyperaccumulator Alyssum murale. Plant Soil 377, 407-422. doi: 10.1007/s11104-013-2003-7

Mei, H., Cheng, N. H., Zhao, J., Park, S., Escareno, R. A., Pittman, J. K., et al. (2009). Root development under metal stress in Arabidopsis thaliana requires the $\mathrm{H}^{+} /$cation antiporter CAX4. New Phytol. 183, 95-105. doi: 10.1111/j.14698137.2009.02831.x

Meinhard, M., Rodriguez, P. L., and Grill, E. (2002). The sensitivity of ABI2 to hydrogen peroxide links the abscisic acid-response regulator to redox signalling. Planta 214, 775-782. doi: 10.1007/s00425-001-0675-3

Membré, N., Bernier, F., Staiger, D., and Berna, A. (2000). Arabidopsis thaliana germin-like proteins: common and specific features point to a variety of functions. Planta 211, 345-354. doi: 10.1007/s004250000277

Meng, J. G., Zhang, X. D., Tan, S. K., Zhao, K. X., and Yang, Z. M. (2017). Genomewide identification of Cd-responsive NRAMP transporter genes and analyzing expression of NRAMP1 mediated by miR167 in Brassica napus. Biometals 30, 917-931. doi: 10.1007/s10534-017-0057-3

Migocka, M., Papierniak, A., Kosieradzka, A., Posyniak, E., MaciaszczykDziubinska, E., Biskup, R., et al. (2015). Cucumber metal tolerance protein CsMTP9 is a plasma membrane $\mathrm{H}^{+}$-coupled antiporter involved in the $\mathrm{Mn}^{2+}$ and $\mathrm{Cd}^{2+}$ efflux from root cells. Plant J. 84, 1045-1058. doi: 10.1111/tpj.13056

Millaleo, R., Reyes-Díaz, M., Alberdi, M., Ivanov, A. G., Krol, M., and Hüner, N. P. A. (2013). Excess manganese differentially inhibits photosystem I versus II in Arabidopsis thaliana. J. Exp. Bot. 64, 343-354. doi: 10.1093/jxb/ers339

Millaleo, R., Reyes-Diaz, M., Ivanov, A. G., Mora, M. L., and Alberdi, M. (2010). Manganese as essential and toxic element for plants: transport, accumulation and resistance mechanisms. J. Soil Sci. Plant Nutr. 10, 470-481. doi: 10.4067/ s0718-95162010000200008

Mills, R. F., Doherty, M. L., Lopez-Marques, R. L., Weimar, T., Dupree, P., Palmgren, M. G., et al. (2007). ECA3, a Golgi-localized $P_{2 A}$-type ATPase, plays a crucial role in manganese nutrition in Arabidopsis. Plant Physiol. 146, 116-128. doi: 10.1104/pp.107.110817

Milner, M. J., Seamon, J., Craft, E., and Kochian, L. V. (2013). Transport properties of members of the ZIP family in plants and their role in $\mathrm{Zn}$ and Mn homeostasis. J. Exp. Bot. 64, 369-381. doi: 10.1093/jxb/ers315

Montanini, B., Blaudez, D., Jeandroz, S., Sanders, D., and Chalot, M. (2007). Phylogenetic and functional analysis of the Cation Diffusion Facilitator (CDF) family: improved signature and prediction of substrate specificity. BMC Genomics 8:107. doi: 10.1186/1471-2164-8-107 
Morgan, J. J. (2005). Kinetics of reaction between $\mathrm{O}_{2}$ and $\mathrm{Mn}$ (II) species in aqueous solutions. Geochim. Cosmochim. Acta 69, 35-48. doi: 10.1016/j.gca.2004. 06.013

Morgan, P. W., Joham, H. E., and Amin, J. V. (1966). Effect of manganese toxicity on the indoleacetic acid oxidase system of cotton. Plant Physiol. 41, 718-724. doi: 10.1104/pp.41.4.718

Morris, J., Tian, H., Park, S., Sreevidya, C. S., Ward, J. M., and Hirschi, K. D. (2008). AtCCX3 is an Arabidopsis endomembrane $\mathrm{H}^{+}$-dependent $\mathrm{K}^{+}$transporter. Plant Physiol. 148, 1474-1486. doi: 10.1104/pp.108.118810

Nable, R. O., Houtz, R. L., and Cheniae, G. M. (1988). Early inhibition of photosynthesis during development of Mn toxicity in tobacco. Plant Physiol. 86, 1136-1142. doi: 10.1104/pp.86.4.1136

Nevo, Y., and Nelson, N. (2006). The NRAMP family of metal-ion transporters. Biochim. Biophys. Acta Mol. Cell Res. 1763, 609-620. doi: 10.1016/j.bbamcr. 2006.05.007

Nian, L. S. (1989). Manganese induced iron chlorosis in pineapple and its control by foliar application of iron-citrate. J. Plant Nutr. Soil Sci. 152, 125-126. doi: 10.1002/jpln.19891520122

Nowicki, M., Müller, F., and Frentzen, M. (2005). Cardiolipin synthase of Arabidopsis thaliana. FEBS Lett. 579, 2161-2165. doi: 10.1016/j.febslet.2005. 03.007

Nuruzzaman, M., Lambers, H., Bolland, M. D. A., and Veneklaas, E. J. (2006). Distribution of carboxylates and acid phosphatase and depletion of different phosphorus fractions in the rhizosphere of a cereal and three grain legumes. Plant Soil 281, 109-120. doi: 10.1007/s11104-005-3936-2

Ohki, K. (1985). Manganese deficiency and toxicity effects on photosynthesis, chlorophyll, and transpiration in Wheat. Crop Sci. 25, 187-191. doi: 10.2135/ cropsci1985.0011183x002500010045x

Önnerud, H., Zhang, L., Gellerstedt, G., and Henriksson, G. (2002). Polymerization of monolignols by redox shuttle-mediated enzymatic oxidation. Plant Cell 14, 1953-1962. doi: 10.1105/tpc.001487

Oomen, R. J. F. J., Wu, J., Lelièvre, F., Blanchet, S., Richaud, P., Barbier-Brygoo, H., et al. (2009). Functional characterization of NRAMP3 and NRAMP4 from the metal hyperaccumulator Thlaspi caerulescens. New Phytol. 181, 637-650. doi: 10.1111/j.1469-8137.2008.02694.x

Panda, S., Mishra, A. K., and Biswal, U. C. (1987). Manganese induced peroxidation of thylakoid lipids and changes in chlorophyll- $\alpha$ fluorescence during aging of cell free chloroplasts in light. Phytochemistry 26, 3217-3219. doi: 10.1016/ s0031-9422(00)82472-3

Papadakis, I. E., Giannakoula, A., Therios, I. N., Bosabalidis, A. M., Moustakas, M., and Nastou, A. (2007). Mn-induced changes in leaf structure and chloroplast ultrastructure of Citrus volkameriana (L.) plants. J. Plant Physiol. 164, 100-103. doi: 10.1016/j.jplph.2006.04.011

Pedas, P., Hebbern, C. A., Schjoerring, J. K., Holm, P. E., and Husted, S. (2005). Differential capacity for high-affinity manganese uptake contributes to differences between barley genotypes in tolerance to low manganese availability. Plant Physiol. 139, 1411-1420. doi: 10.1104/pp.105.067561

Pedas, P., Husted, S., Skytte, K., and Schjoerring, J. K. (2011). Elevated phosphorus impedes manganese acquisition by barley plants. Front. Plant Sci. 2:37. doi: 10.3389/fpls.2011.00037

Pedas, P., Stokholm, M. S., Hegelund, J. N., Ladegård, A. H., Schjoerring, J. K., and Husted, S. (2014). Golgi localized barley MTP8 proteins facilitate Mn transport. PLoS One 9:e113759. doi: 10.1371/journal.pone.0113759

Pedas, P., Ytting, C. K., Fuglsang, A. T., Jahn, T. P., Schjoerring, J. K., and Husted, S. (2008). Manganese efficiency in barley: identification and characterization of the metal ion transporter HvIRT1. Plant Physiol. 148, 455-466. doi: 10.1104/pp. 108.118851

Peiter, E., Montanini, B., Gobert, A., Pedas, P., Husted, S., Maathuis, F. J. M., et al. (2007). A secretory pathway-localized cation diffusion facilitator confers plant manganese tolerance. Proc. Natl. Acad. Sci. U.S.A. 104, 8532-8537. doi: 10.1073/pnas.0609507104

Peris-Peris, C., Serra-Cardona, A., Sánchez-Sanuy, F., Campo, S., Ariño, J., and San Segundo, B. (2017). Two NRAMP6 isoforms function as iron and manganese transporters and contribute to disease resistance in rice. Mol. Plant Microbe Interact. 30, 385-398. doi: 10.1094/MPMI-01-17-0005-R

Pittman, J. K. (2005). Managing the manganese: molecular mechanisms of manganese transport and homeostasis. New Phytol. 167, 733-742. doi: 10.1111/ j.1469-8137.2005.01453.x
Pittman, J. K., and Hirschi, K. D. (2016). Phylogenetic analysis and protein structure modelling identifies distinct $\mathrm{Ca}^{2+} /$ cation antiporters and conservation of gene family structure within Arabidopsis and rice species. Rice 9:3. doi: 10.1186/s12284-016-0075-8

Pittman, J. K., Shigaki, T., Marshall, J. L., Morris, J. L., Cheng, N., and Hirschi, K. D. (2004). Functional and regulatory analysis of the Arabidopsis thaliana CAX2 cation transporter. Plant Mol. Biol. 56, 959-971. doi: 10.1007/s11103004-6446-3

Pottier, M., Oomen, R., Picco, C., Giraudat, J., Scholz-Starke, J., Richaud, P., et al. (2015). Identification of mutations allowing natural resistance associated macrophage proteins (NRAMP) to discriminate against cadmium. Plant J. 83, 625-637. doi: 10.1111/tpj.12914

Reddi, A. R., Jensen, L. T., Naranuntarat, A., Rosenfeld, L., Leung, E., Shah, R., et al. (2009). The overlapping roles of manganese and $\mathrm{Cu} / \mathrm{Zn}$ SOD in oxidative stress protection. Free Radic. Biol. Med. 46, 154-162. doi: 10.1016/j.freeradbiomed. 2008.09.032

Rengel, Z. (2015). Availability of Mn, Zn and Fe in the rhizosphere. J. Soil Sci. Plant Nutr. 15, 397-409.

Requena, L., and Bornemann, S. (1999). Barley (Hordeum vulgare) oxalate oxidase is a manganese-containing enzyme. Biochem. J. 343, 185-190. doi: 10.1042/ bj3430185

Robert, H. S., and Offringa, R. (2008). Regulation of auxin transport polarity by AGC kinases. Curr. Opin. Plant Biol. 11, 495-502. doi: 10.1016/j.pbi.2008.06. 004

Rodríguez-Celma, J., Tsai, Y.-H., Wen, T.-N., Wu, Y.-C., Curie, C., and Schmidt, W. (2016). Systems-wide analysis of manganese deficiency-induced changes in gene activity of Arabidopsis roots. Sci. Rep. 6, 35846-35846. doi: 10.1038/ srep35846

Rohdich, F., Lauw, S., Kaiser, J., Feicht, R., Köhler, P., Bacher, A., et al. (2006). Isoprenoid biosynthesis in plants - 2C-methyl-D-erythritol-4-phosphate synthase (IspC protein) of Arabidopsis thaliana. FEBS J. 273, 4446-4458. doi: $10.1111 /$ j.1742-4658.2006.05446.x

Rohdich, F., Wungsintaweekul, J., Eisenreich, W., Richter, G., Schuhr, C. A., Hecht, S., et al. (2000). Biosynthesis of terpenoids: 4-diphosphocytidyl-2C-methyl-Derythritol synthase of Arabidopsis thaliana. Proc. Natl. Acad. Sci. U.S.A. 97, 6451-6456. doi: 10.1073/pnas.97.12.6451

Sasaki, A., Yamaji, N., Xia, J., and Ma, J. F. (2011). OsYSL6 is involved in the detoxification of excess manganese in rice. Plant Physiol. 157, 1832-1840. doi: 10.1104/pp.111.186031

Sasaki, A., Yamaji, N., Yokosho, K., and Ma, J. F. (2012). Nramp5 is a major transporter responsible for manganese and cadmium uptake in rice. Plant Cell 24, 2155-2167. doi: 10.1105/tpc.112.096925

Schaaf, G., Ludewig, U., Erenoglu, B. E., Mori, S., Kitahara, T., and von Wirén, N. (2004). ZmYS1 functions as a proton-coupled symporter for phytosiderophoreand nicotianamine-chelated metals. J. Biol. Chem. 279, 9091-9096. doi: 10. 1074/jbc.m311799200

Schenk, G., Ge, Y., Carrington, L. E., Wynne, C. J., Searle, I. R., Carroll, B. J., et al. (1999). Binuclear metal centers in plant purple acid phosphatases: Fe-Zn in sweet potato and Fe-Zn in soybean. Arch. Biochem. Biophys. 370, 183-189. doi: 10.1006/abbi.1999.1407

Schmidt, S. B., Jensen, P. E., and Husted, S. (2016). Manganese deficiency in plants: The impact on photosystem II. Trends Plant Sci. 21, 622-632. doi: 10.1016/j. tplants.2016.03.001

Schneider, A., Steinberger, I., Herdean, A., Gandini, C., Eisenhut, M., Kurz, S., et al. (2016). The evolutionarily conserved protein PHOTOSYNTHESIS AFFECTED MUTANT71 is required for efficient manganese uptake at the thylakoid membrane in Arabidopsis. Plant Cell 28, 892-910. doi: 10.1105/tpc. 15.00812

Schweighofer, A., Hirt, H., and Meskiene, I. (2004). Plant PP2C phosphatases: Emerging functions in stress signaling. Trends Plant Sci. 9, 236-243. doi: 10.1016/j.tplants.2004.03.007

Sello, S., Moscatiello, R., Mehlmer, N., Leonardelli, M., Carraretto, L., Cortese, E., et al. (2018). Chloroplast $\mathrm{Ca}^{2+}$ fluxes into and across thylakoids revealed by thylakoid-targeted aequorin probes. Plant Physiol. 177, 38-51. doi: 10.1104/pp. 18.00027

Shao, J. F., Yamaji, N., Shen, R. F., and Ma, J. F. (2017). The key to Mn homeostasis in plants: regulation of Mn transporters. Trends Plant Sci. 22, 215-224. doi: 10.1016/j.tplants.2016.12.005 
Shigaki, T., Pittman, J. K., and Hirschi, K. D. (2003). Manganese specificity determinants in the Arabidopsis metal/ $\mathrm{H}^{+}$antiporter CAX2. J. Biol. Chem. 278, 6610-6617. doi: 10.1074/jbc.M209952200

Socha, A. L., and Guerinot, M. L. (2014). Mn-euvering manganese: the role of transporter gene family members in manganese uptake and mobilization in plants. Front. Plant Sci. 5:106. doi: 10.3389/fpls.2014.00106

Sparrow, L. A., and Uren, N. C. (2014). Manganese oxidation and reduction in soils: effects of temperature, water potential, $\mathrm{pH}$ and their interactions. Soil Res. 52, 483-494. doi: 10.1071/SR13159

St.Clair, S. B., and Lynch, J. P. (2005). Element accumulation patterns of deciduous and evergreen tree seedlings on acid soils: implications for sensitivity to manganese toxicity. Tree Physiol. 25, 85-92. doi: 10.1093/treephys/25.1.85

Stael, S., Wurzinger, B., Mair, A., Mehlmer, N., Vothknecht, U. C., and Teige, M. (2012). Plant organellar calcium signalling: an emerging field. J. Exp. Bot. 63, 1525-1542. doi: 10.1093/jxb/err394

Stengel, A., Gügel, I. L., Hilger, D., Rengstl, B., Jung, H., and Nickelsen, J. (2012). Initial steps of photosystem II de novo assembly and preloading with manganese take place in biogenesis centers in Synechocystis. Plant Cell 24, 660-675. doi: 10.1105/tpc.111.093914

Stoltz, E., and Wallenhammar, A. C. (2014). Manganese application increases winter hardiness in barley. Field Crops Res. 164, 148-153. doi: 10.1016/j.fcr. 2014.05.008

Strasser, R., Bondili, J. S., Vavra, U., Schoberer, J., Svoboda, B., Glossl, J., et al. (2007). A unique $\beta 1$,3-galactosyltransferase is indispensable for the biosynthesis of N-glycans containing Lewis a structures in Arabidopsis thaliana. Plant Cell 19, 2278-2292. doi: 10.1105/tpc.107.052985

Stumm, W., and Morgan, J. J. (1996). Aquatic Chemistry: Chemical Equilibria and Rates in Natural Waters. New York, NY: Wiley.

Subrahmanyam, D., and Rathore, V. S. (2001). Influence of manganese toxicity on photosynthesis in ricebean (Vigna umbellata) seedlings. Photosynthetica 38 , 449-453.

Svedruzic, D., Jonsson, S., Toyota, C. G., Reinhardt, L. A., Ricagno, S., Lindqvist, Y., et al. (2005). The enzymes of oxalate metabolism: unexpected structures and mechanisms. Arch. Biochem. Biophys. 433, 176-192. doi: 10.1016/j.abb.2004.08. 032

Szurmak, B., Wysłouch-Cieszyńska, A., Wszelaka-Rylik, M., Bal, W., and Dobrzańska, M. (2008). A diadenosine $5^{\prime}, 5^{\prime \prime}-\mathrm{P} 1 \mathrm{P} 4$ tetraphosphate $\left(\mathrm{Ap}_{4} \mathrm{~A}\right)$ hydrolase from Arabidopsis thaliana that is activated preferentially by $\mathrm{Mn}^{2+}$ ions. Acta Biochim. Polon. 55, 151-160. doi: 10.18388/abp.2008_3173

Takahashi, S., Sakamoto, A. N., Tanaka, A., and Shimizu, K. (2007). AtREV1, a Y-family DNA polymerase in Arabidopsis, has deoxynucleotidyl transferase activity in vitro. Plant Physiol. 145, 1052-1060. doi: 10.1104/pp.107.101980

Takemoto, Y., Tsunemitsu, Y., Fujii-Kashino, M., Mitani-Ueno, N., Yamaji, N., Ma, J. F., et al. (2017). The tonoplast-localized transporter MTP8.2 contributes to manganese detoxification in the shoots and roots of Oryza sativa L. Plant Cell Physiol. 58, 1573-1582. doi: 10.1093/pcp/pcx082

Teardo, E., Carraretto, L., Moscatiello, R., Cortese, E., Vicario, M., Festa, M., et al. (2019). A chloroplast-localized mitochondrial calcium uniporter transduces osmotic stress in Arabidopsis. Nat. Plants 5, 581-588. doi: 10.1038/s41477-0190434-8

Thomine, S., Lelièvre, F., Debarbieux, E., Schroeder, J. I., and Barbier-Brygoo, H. (2003). AtNRAMP3, a multispecific vacuolar metal transporter involved in plant responses to iron deficiency. Plant J. 34, 685-695. doi: 10.1046/j.1365313X.2003.01760.x

Thomine, S., Wang, R., Ward, J. M., Crawford, N. M., and Schroeder, J. I. (2000). Cadmium and iron transport by members of a plant metal transporter family in Arabidopsis with homology to Nramp genes. Proc. Natl. Acad. Sci. U.S.A. 97, 4991-4996. doi: 10.1073/pnas.97.9.4991

Tiwari, M., Sharma, D., Dwivedi, S., Singh, M., Tripathi, R. D., and Trivedi, P. K. (2014). Expression in Arabidopsis and cellular localization reveal involvement of rice NRAMP, OsNRAMP1, in arsenic transport and tolerance. Plant Cell Environ. 37, 140-152. doi: 10.1111/pce.12138

Tsukamoto, T., Nakanishi, H., Kiyomiya, S., Watanabe, S., Matsuhashi, S., Nishizawa, N. K., et al. (2006). ${ }^{52} \mathrm{Mn}$ translocation in barley monitored using a positron-emitting tracer imaging system. Soil Sci. Plant Nutr. 52, 717-725. doi: 10.1111/j.1747-0765.2006.00096.x

Tsunemitsu, Y., Genga, M., Okada, T., Yamaji, N., Ma, J. F., Miyazaki, A., et al. (2018). A member of cation diffusion facilitator family, MTP11, is required for manganese tolerance and high fertility in rice. Planta 248, 231-241. doi: 10.1007/s00425-018-2890-1

Turekian, K. K., and Wedepohl, K. H. (1961). Distribution of the elements in some major units of the earth's crust. GSA Bull. 72, 175-192.

Ueno, D., Sasaki, A., Yamaji, N., Miyaji, T., Fujii, Y., Takemoto, Y., et al. (2015). A polarly localized transporter for efficient manganese uptake in rice. Nat. Plants 1:15170. doi: 10.1038/nplants.2015.170

Ullah, I., Wang, Y., Eide, D. J., and Dunwell, J. M. (2018). Evolution, and functional analysis of natural resistance-associated macrophage proteins (NRAMPs) from Theobroma cacao and their role in cadmium accumulation. Sci. Rep. 8:14412. doi: 10.1038/s41598-018-32819-y

Venkidasamy, B., Selvaraj, D., and Ramalingam, S. (2019). Genome-wide analysis of purple acid phosphatase (PAP) family proteins in Jatropha curcas L. Int. J. Biol. Macromol. 123, 648-656. doi: 10.1016/j.ijbiomac.2018.11.027

Vert, G., Grotz, N., Dédaldéchamp, F., Gaymard, F., Guerinot, M., Lou, B. J., et al. (2002). IRT1, an Arabidopsis transporter essential for iron uptake from the soil and for plant growth. Plant Cell 14, 1223-1233. doi: 10.1105/tpc.001388

Wagner, S., Behera, S., De Bortoli, S., Logan, D. C., Fuchs, P., Carraretto, L., et al. (2015). The EF-hand $\mathrm{Ca}^{2+}$ binding protein MICU choreographs mitochondrial $\mathrm{Ca}^{2+}$ dynamics in Arabidopsis. Plant Cell 27, 3190-3212. doi: 10.1105/tpc.15. 00509

Wang, C., Guan, Y., Lv, M., Zhang, R., Guo, Z., Wei, X., et al. (2018). Manganese increases the sensitivity of the cGAS-STING pathway for double-stranded DNA and is required for the host defense against DNA viruses. Immunity 48, 675.e7-687.e7. doi: 10.1016/j.immuni.2018.03.017

Wang, C., Xu, W., Jin, H., Zhang, T., Lai, J., Zhou, X., et al. (2016). A putative chloroplast-localized $\mathrm{Ca}^{2+} / \mathrm{H}^{+}$antiporter CCHAl is involved in calcium and $\mathrm{pH}$ homeostasis and required for PSII function in Arabidopsis. Mol. Plant 9, 1183-1196. doi: 10.1016/j.molp.2016.05.015

Wang, N., Qiu, W., Dai, J., Guo, X., Lu, Q., Wang, T., et al. (2019). AhNRAMP1 enhances manganese and zinc uptake in plants. Front. Plant Sci. 10:415. doi: $10.3389 /$ fpls.2019.00415

Wang, X., Zhong, F., Woo, C. H., Miao, Y., Grusak, M. A., Zhang, X., et al. (2017). A rapid and efficient method to study the function of crop plant transporters in Arabidopsis. Protoplasma 254, 737-747. doi: 10.1007/s00709-0160987-6

Waters, B. M., Chu, H. H., Didonato, R. J., Roberts, L. A., Eisley, R. B., Lahner, B., et al. (2006). Mutations in Arabidopsis Yellow Stripe-Like1 and Yellow StripeLike3 reveal their roles in metal ion homeostasis and loading of metal ions in seeds. Plant Physiol. 141, 1446-1458. doi: 10.1104/pp.106.082586

Werner, A. K., Sparkes, I. A., Romeis, T., and Witte, C. P. (2008). Identification, biochemical characterization, and subcellular localization of allantoate amidohydrolases from Arabidopsis and soybean. Plant Physiol. 146, 418-430. doi: 10.1104/pp.107.110809

White, P. J., Bowen, H. C., Demidchik, V., Nichols, C., and Davies, J. M. (2002). Genes for calcium-permeable channels in the plasma membrane of plant root cells. Biochim. Biophys. Acta Biomembr. 1564, 299-309. doi: 10.1016/S00052736(02)00509-6

White, P. J., and Greenwood, D. J. (2013). "Properties and management of cationic elements for crop growth," in Soil Conditions and Plant Growth, eds P. J. Gregory and S. Nortcliff (Oxford: Blackwell Publishing), 160-194 doi: 10.1002/ 9781118337295.ch6

Wilkinson, R. E., and Ohki, K. (1988). Influence of manganese deficiency and toxicity on isoprenoid syntheses. Plant Physiol. 87, 841-846. doi: 10.1104/pp. 87.4.841

Wu, D., Yamaji, N., Yamane, M., Kashino-Fujii, M., Sato, K., and Ma, J. F. (2016). The HvNramp5 transporter mediates uptake of cadmium and manganese, but not iron. Plant Physiol. 172, 1899-1910. doi: 10.1104/pp.16.01189

Wu, Z., Liang, F., Hong, B., Young, J. C., Sussman, M. R., Harper, J. F., et al. (2002). An endoplasmic reticulum-bound $\mathrm{Ca}^{2+} / \mathrm{Mn}^{2+}$ pump, ECA1, supports plant growth and confers tolerance to $\mathrm{Mn}^{2+}$ stress. Plant Physiol. 130, 128-137. doi: $10.1104 /$ pp. 004440

Wymer, C. L., Bibikova, T. N., and Gilroy, S. (1997). Cytoplasmic free calcium distributions during the development of root hairs of Arabidopsis thaliana. Plant J. 12, 427-439. doi: 10.1046/j.1365-313X.1997.12020427.x

Xia, J., Yamaji, N., Kasai, T., and Ma, J. F. (2010). Plasma membrane-localized transporter for aluminum in rice. Proc. Natl. Acad. Sci. U.S.A. 107, 1838118385. doi: $10.1073 /$ pnas. 1004949107 
Xiao, H., Yin, L., Xu, X., Li, T., and Han, Z. (2008). The iron-regulated transporter, MbNRAMP1, isolated from Malus baccata is involved in Fe, Mn and Cd trafficking. Ann. Bot. 102, 881-889. doi: 10.1093/aob/mcn 178

Yamada, K., Hara-Nishimura, I., and Nishimura, M. (2011). Unique defense strategy by the endoplasmic reticulum body in plants. Plant Cell Physiol. 52, 2039-2049. doi: 10.1093/pcp/pcr156

Yamada, K., Nagano, A. J., Nishina, M., Hara-Nishimura, I., and Nishimura, M. (2013). Identification of two novel endoplasmic reticulum body-specific integral membrane proteins. Plant Physiol. 161, 108-120. doi: 10.1104/pp.112.207654

Yamada, N., Theerawitaya, C., Cha-Um, S., Kirdmanee, C., and Takabe, T. (2014). Expression and functional analysis of putative vacuolar $\mathrm{Ca}^{2+}$-transporters (CAXs and ACAs) in roots of salt tolerant and sensitive rice cultivars. Protoplasma 251, 1067-1075. doi: 10.1007/s00709-014-0615-2

Yamaji, N., Sasaki, A., Xia, J. X., Yokosho, K., and Ma, J. F. (2013). A node-based switch for preferential distribution of manganese in rice. Nat. Commun. 4:2442. doi: $10.1038 /$ ncomms3442

Yang, M., Zhang, W., Dong, H., Zhang, Y., Lv, K., Wang, D., et al. (2013). OsNRAMP3 is a vascular bundles-specific manganese transporter that is responsible for manganese distribution in rice. PLoS One 8:e83990. doi: 10 . 1371/journal.pone.0083990

Yang, M., Zhang, Y., Zhang, L., Hu, J., Zhang, X., Lu, K., et al. (2014). OsNRAMP5 contributes to manganese translocation and distribution in rice shoots. J. Exp. Bot. 65, 4849-4861. doi: 10.1093/jxb/eru259

Yang, T. J. W., Perry, P. J., Ciani, S., Pandian, S., and Schmidt, W. (2008). Manganese deficiency alters the patterning and development of root hairs in Arabidopsis. J. Exp. Bot. 59, 3453-3464. doi: 10.1093/jxb/ern195

Zhang, B., Zhang, C., Liu, C., Jing, Y., Wang, Y., Jin, L., et al. (2018). Inner envelope CHLOROPLAST MANGANESE TRANSPORTER 1 supports manganese homeostasis and phototrophic growth in Arabidopsis. Mol. Plant 11, 943-954. doi: 10.1016/j.molp.2018.04.007

Zhang, M., and Liu, B. (2017). Identification of a rice metal tolerance protein OsMTP11 as a manganese transporter. PLoS One 12:e0174987. doi: 10.1371/ journal.pone.0174987

Zhang, Y., Xu, Y. H., Yi, H. Y., and Gong, J. M. (2012). Vacuolar membrane transporters OsVIT1 and OsVIT2 modulate iron translocation between flag leaves and seeds in rice. Plant J. 72, 400-410. doi: 10.1111/j.1365-313X.2012. 05088.x

Zhang, Z., Yin, H., Tan, W., Koopal, L. K., Zheng, L., Feng, X., et al. (2014). Zn sorption to biogenic bixbyite-like $\mathrm{Mn}_{2} \mathrm{O}_{3}$ produced by Bacillus CUA isolated from soil: XAFS study with constraints on sorption mechanism. Chem. Geol. 389, 82-90. doi: 10.1016/j.chemgeo.2014.09.017

Zhao, J., Wang, W., Zhou, H., Wang, R., Zhang, P., Wang, H., et al. (2017). Manganese toxicity inhibited root growth by disrupting auxin biosynthesis and transport in Arabidopsis. Front. Plant Sci. 8:272. doi: 10.3389/fpls.2017. 00272

Conflict of Interest: The authors declare that the research was conducted in the absence of any commercial or financial relationships that could be construed as a potential conflict of interest.

Copyright (c) 2020 Alejandro, Höller, Meier and Peiter. This is an open-access article distributed under the terms of the Creative Commons Attribution License (CC BY). The use, distribution or reproduction in other forums is permitted, provided the original author(s) and the copyright owner(s) are credited and that the original publication in this journal is cited, in accordance with accepted academic practice. No use, distribution or reproduction is permitted which does not comply with these terms. 